\title{
Behavioral and psychological symptoms of dementia
}

\author{
J. Cerejeira ${ }^{1}$, L. Lagarto ${ }^{1}$ and E. B. Mukaetova-Ladinska ${ }^{2}$ \\ Serviço de Psiquiatria, Centro Hospitalar Psiquiátrico de Coimbra, Coimbra, Portugal \\ ${ }^{2}$ Institute for Ageing and Health, Newcastle University, Newcastle upon Tyne, UK
}

\section{Edited by:}

João Massano, Centro Hospitalar de São João and Faculty of Medicine University of Porto, Portugal

Reviewed by:

Federica Agosta, Vita-Salute San Raffaele University, Italy

Luísa Alves, Centro Hospitalar de Lisboa Ocidental, Portugal

\section{${ }^{*}$ Correspondence:}

J. Cerejeira, Serviço de Psiquiatria, Centro Hospitalar Psiquiátrico de Coimbra, Coimbra 3000-377, Portugal. e-mail: jcerejeira@netcabo.pt
Behavioral and psychological symptoms of dementia (BPSD), also known as neuropsychiatric symptoms, represent a heterogeneous group of non-cognitive symptoms and behaviors occurring in subjects with dementia. BPSD constitute a major component of the dementia syndrome irrespective of its subtype. They are as clinically relevant as cognitive symptoms as they strongly correlate with the degree of functional and cognitive impairment. BPSD include agitation, aberrant motor behavior, anxiety, elation, irritability, depression, apathy, disinhibition, delusions, hallucinations, and sleep or appetite changes. It is estimated that BPSD affect up to $90 \%$ of all dementia subjects over the course of their illness, and is independently associated with poor outcomes, including distress among patients and caregivers, long-term hospitalization, misuse of medication, and increased health care costs. Although these symptoms can be present individually it is more common that various psychopathological features co-occur simultaneously in the same patient. Thus, categorization of BPSD in clusters taking into account their natural course, prognosis, and treatment response may be useful in the clinical practice. The pathogenesis of BPSD has not been clearly delineated but it is probably the result of a complex interplay of psychological, social, and biological factors. Recent studies have emphasized the role of neurochemical, neuropathological, and genetic factors underlying the clinical manifestations of BPSD. A high degree of clinical expertise is crucial to appropriately recognize and manage the neuropsychiatric symptoms in a patient with dementia. Combination of non-pharmacological and careful use of pharmacological interventions is the recommended therapeutic for managing BPSD. Given the modest efficacy of current strategies, there is an urgent need to identify novel pharmacological targets and develop new non-pharmacological approaches to improve the adverse outcomes associated with BPSD.

Keywords: behavioral and psychological symptoms, dementia, neuropsychiatric symptoms, Alzheimer's disease

\section{INTRODUCTION}

During the natural course of dementia a heterogeneous group of clinical phenomena is subjectively experienced by the patient and/or observable by an examiner (e.g., caregiver, physician) consisting in disturbed emotions, mood, perception, thought, motor activity, and altered personality traits. These "neuropsychiatric symptoms," according to the terminology most used in the United States, or "behavioral and psychological symptoms of dementia" (BPSD), as designated by the International Psychogeriatrics Association (Finkel et al., 1996), are very common and associated with high levels of distress both in dementia sufferers and their caregivers, as well as with adverse outcomes and increased use of health care resources. Thus, in addition to cognitive deterioration, BPSD are a relevant and meaningful clinical target for intervention (Katona et al., 2007).

\section{BPSD: CONCEPTUAL OVERVIEW \\ BPSD IN THE CURRENT CLASSIFICATION SYSTEMS}

Despite being almost universally present during the course of dementia, BPSD have not been included in the defining criteria of dementia in the current classification systems. The core features of dementia according to DSM-IV-TR and ICD-10 consist of gradual onset of multiple cognitive deficits (involving memory and at least one additional cognitive domain) not occurring exclusively during delirium and representing a decline from a previous level of functioning (American Psychiatric Association, 1994). In DSM-IV-TR the presence or absence of a clinically significant behavioral disturbance can be coded, but no guidance is provided about the diagnostic criteria of these symptoms. It is also possible to code dementia (e.g., Alzheimer disease, AD) in axis III and specific mental disorders (e.g., mood or psychotic disorder) in axis I with the advantage of better characterizing prominent clinical features related to dementia (American Psychiatric Association, 1994).

\section{PSYCHOPATHOLOGICAL FEATURES}

Neuropsychiatric symptoms in subjects with dementia are heterogeneous and largely unpredictable, affecting the emotional experience, thought content, perception, and motor function. While some symptoms can be more often recognized in a specific pathological sub-type, the clinical presentation has a wide variation within each sub-type and even within each dementia individual. The first step to better understand the psychiatric manifestations of dementia is to appropriately recognize and describe 
the psychopathology and accurately distinguish between similar symptoms (e.g., depression vs. apathy). This can be challenging considering the overlap between symptoms and the lack of proper definitions and consensus criteria for their diagnosis. Secondly, it is useful to evaluate whether specific symptoms occur in association and to group them in syndromes with common clinical evolution, neurobiology, and management.

\section{Disturbances in emotional experience}

As the symptoms of depression are frequently masked by dementia, the patient rarely is able to express the typical pathological feelings of sadness, unhappiness, and preoccupation with depressing topics, hopeless (strongly associated with suicidal ideation) and loss of self-esteem (Prado-Jean et al., 2010). Instead, the prominent symptoms can be anhedonia (lost of interest in previous pleasurable stimuli), expression of somatic concerns and anxiety, a subjective unpleasant experience of fear manifested as apprehension, tension, panic, or worry associated with autonomic activation and observable physical and motor manifestations of tension. In the context of dementia, apathy has been defined as a disorder of motivation with additional loss or diminished goal-directed behaviors, cognitive activities and emotions (Robert et al., 2009). Apathy may be mistaken for depression because both symptoms can manifest themselves as diminished interest, slowing and lack of energy (Mulin et al., 2011). Although lack of motivation occurs both in apathy and depression, apathy denotes a lack of motivation without dysphoria. Elated mood, ranging from hypomania to severe mania, refers to a sustained and exaggerated feeling of well-being, cheerfulness, euphoria that is out of proportion to the circumstances often associated with a heightened emotional tone or emotional reactivity. Both depression and elated mood are commonly associated with irritability, a pervasive feeling of unease in response to a sense of threat with enhanced readiness to hostile attitudes or actions, which can be aggravated by hunger, sleepiness, and pain. Affective (or mood) lability is characterized by rapid emotional shifts, within seconds or minutes.

\section{Delusions and abnormal thought content}

Delusional ideas (false believes strongly held, enduring, and irrefutable) can vary widely in respect to complexity, systematization, conviction, and the extent to which patients take action in response to them. The delusions are typically less complex and organized than those observed in non-demented psychotic patients and the usual content of delusional thoughts involves suspiciousness, abandonment, and misidentification (Jeste et al., 2006). Common examples include the conviction that: people are coming into the home and hiding/stealing objects; the place in which one is residing is not one's home; conviction that spouse is an impostor (Capgras delusion); accusation of a conspiracy to abandon or institutionalize; conviction that spouse is unfaithful; believes that other persons have acted maliciously; or with discriminatory intent (Tariot et al., 1995). When associated with severe depression, delusional thoughts can involve guilt, worthless, reference, and persecution.

\section{PERCEPTUAL DISTURBANCES}

Perceptual disturbances in dementia can occur in every sensorial modality. In some instances, it is somewhat difficult to ascertain whether the perceptual disturbance is an illusion or whether the patient is having a perception in the absence of sensory stimuli (hallucination). Visual hallucinations are particularly common in subjects with dementia with Lewy bodies (DLB). They are recurrent, and typically consist of well formed images of animals or persons that the patient describes in detail (McKeith et al., 2005).

\section{DISTURBANCES IN MOTOR FUNCTION}

Unlike the prior psychopathological domains, disturbances in motor function can be directly observed and consist in reduced or increased motor activity, not necessarily associated with specific motor abnormalities. In motor retardation the patient presents with slowed movements and speech, reduced body tone, and decreased number of spontaneous body movements, whereas motor hyperactivity is characterized by an increased energy level with more frequent movements and/or rapid speech.

Agitation has been defined as "inappropriate verbal, vocal, or motor activity that is not judged by an outside observer to result directly from the needs or confusion of the agitated individual" (Cohen-Mansfield et al., 2010). This term is used interchangeably with aberrant motor behavior and encompasses a range of activities such as wandering away from home; repetitive, purposeless behaviors; social inappropriate activities including those associated with disinhibition (tendency to disregard social and cultural norms and not restrain inner feelings, such as sexual drives). According to Cohen-Mansfield (1999) four distinct categories of agitation are: (1) physically non-aggressive behavior; (2) verbally non-aggressive behavior; (3) physically aggressive behavior; and (4) verbally aggressive behavior.

\section{CIRCADIAN RHYTHMS}

Sleep pattern changes may occur as a consequence of normal aging, but are particularly prevalent in individuals with dementia. These include hypersomnia, insomnia, sleep-wake cycle reversal, fragmented sleep, and rapid eye movement sleep behavior disorder. Patients with dementia often show daytime napping and nighttime awakenings associated with poor quality of sleep (Rongve et al., 2010). Several factors, e.g., pain, need to urinate during the night, medications (diuretics), as well as stimulants such as coffee and bronchodilators, may contribute to this problem.

\section{APPETITE AND EATING BEHAVIOR}

Appetite changes can be quantitative (anorexia or hyperphagia) or qualitative (preference for particular foods associated or not to changes in taste). The preference for sweets is particularly frequent in fronto-temporal dementia. Most dementia patients lose weight which can be due to hypermetabolism and inflammatory processes, in relation with hormonal disturbances.

\section{BPSD ASSESSMENT}

The assessment of neuropsychiatric symptoms requires a thorough examination to collect specific and detailed information about the clinical history, patient's subjective experiences, and objective behavior. Information from a reliable family member or caregiver is essential to obtain adequate characterization of neuropsychiatric disturbances from the patient's own ecological context as many abnormal symptoms cannot be elicited during the clinical interview. When determining whether the disturbances require medical 
attention it is useful to promote early interventions instead of a crisis-based or reactionary approach.

\section{INTERVIEW WITH THE PATIENT}

Although subjects with dementia may be handicapped in their communication and social skills, it is essential to have an individual assessment with them. Whenever possible, it is desirable that patients are encouraged to express their own concerns in answer to open questions before proceeding to a more systematic approach to specific symptoms. Patient's free descriptions are least prone to be influenced by the interviewer and/or caregiver and can provide crucial information about emotional states underlying behaviors.

\section{CAREGIVER INTERVIEW}

The interview with caregivers is an opportunity to characterize the psychopathological features and to recognize which BPSD are of greatest concern to them as these may not necessarily coincide with the patient's own complaints or with the clinician's priorities.

Understanding the sources of these discrepancies is important to determine the usefulness and limitations of the information obtained from both patients and caregivers as caregiver's emotional state can influence assessment ratings (Logsdon et al., 1999; Snow et al., 2005; Karlawish et al., 2008). In some parts of the assessment, it is important to observe how caregivers interact with the patient and how symptoms are manifested in such interactions. Behavioral symptoms, particularly apathy, have a significant impact in the patient-caregiver relationship deterioration (de Vugt et al., 2003) and subjects with dementia are likely to be affected by dysfunctional interactions with their caregivers (de Vugt et al., 2004; Sink et al., 2006). Caregiver's characteristics, such as younger age, less education, depressive symptoms, and more hours per week providing care assistance, appear to contribute to the presence of or reported higher rates of BPSD (Sink et al., 2006). However, more research is needed to clarify how the patient-caregiver interpersonal interactions contribute to the presence of certain neuropsychiatric symptoms.

\section{STANDARDIZED CLINICAL ASSESSMENT}

Several validated instruments have been developed to quantify BPSD based on data collected from clinical assessment of dementia patients and caregivers' interviews with some scales assessing a wide range of neuropsychiatric symptoms and others focusing on specific symptoms (e.g., aggression and agitation). Self-administered questionnaires are also available for caregivers.

The first behavior rating scale for $\mathrm{AD}$ was the BEHAVE-AD (Reisberg et al., 1987), evaluating the presence and severity of 25 behavioral symptoms in 7 symptomatic categories (paranoid and delusional ideation, hallucination, activity disturbances, aggressiveness, sleep disturbances, affective symptoms, and anxieties and phobias), and providing a global rating of caregiver burden. Currently, one of the most extensively used instruments to assess BPSD is the Neuropsychiatric Inventory (NPI) whose validity and reliability has been well established in several languages (Cummings, 1997). It consists of a semi-structured interview retrospectively assessing 12 symptoms based on the caregiver information: delusions, hallucinations, agitation, depression, anxiety, apathy, irritability, euphoria, disinhibition, aberrant motor behavior, night time behavior disturbances, and eating behavior abnormalities. Important factors to take into account when selecting an instrument include the purpose of the assessment (e.g., comprehensive vs. specific symptom evaluation) and the setting (e.g. busy clinical practice vs. research). When possible, it is advisable to obtain information from different caregivers to cover behavior in different settings, and thus providing an overall picture of patient's functioning. Disagreements among informants should be regarded as a valuable cue to identify situational factors implicated in the genesis of symptoms. It is unlikely that new rating scales will completely solve the problems that are inherent in the assessment of BPSD. Yet, future challenges lie in the improvement of the construction and the use of the scales with an increasing need for more standardized assessment of BPSD and for evaluation of their treatment.

\section{CLINICAL RELEVANCE OF BPSD}

\section{PREVALENCE AND SEVERITY OF INDIVIDUAL SYMPTOMS}

There is an overall agreement that BPSD are very common regardless of the type of dementia and are present in virtually all patients during the course of their disease. Even in the early stages of cognitive impairment, neuropsychiatric symptoms are frequent with estimated rates of $35-85 \%$ in subjects with mild cognitive impairment (MCI; Monastero et al., 2009).

The reported frequency of BPSD largely depends on the type of sample and setting considered. In community-dwelling subjects with dementia, neuropsychiatric symptoms are generally less frequent (56-98\%) and severe than in patients recruited in hospital or long-term care facilities (91-96\%). When looking at individual symptoms in dementia patients, the most prevalent BPSD are apathy, depression, irritability, agitation and anxiety, while the rarest are euphoria, hallucinations, and disinhibition. The most clinically significant symptoms are depression, apathy, and anxiety. Importantly, 50\% of patients have at least four neuropsychiatric symptoms simultaneously (Frisoni et al., 1999).

\section{THE BURDEN OF BPSD}

BPSD are a source of significant distress and poor quality of life (QoL) to both dementia patients and their caregivers (Ryu et al., 2011). In AD patients, depressive symptoms are associated with worse self-reported QoL scores (Karttunen et al., 2011) whereas mood and psychotic symptoms predict changes in the QoL 2 years later (Tatsumi et al., 2009). Moreover, increased number of BPSD correlates negatively with survival rates over a 3-year period (Tun et al., 2007) whereas presence of psychosis in AD has been found to be associated with increased mortality and acceleration of cognitive decline (Emanuel et al., 2011; Russ et al., 2011).

BPSD also have a profound physical and psychological impact on both formal and informal caregivers. A considerable part of caregivers' time and distress relate directly to the manifestation of BPSD (Ballard et al., 2000a), which is a major reason for earlier institutionalization of patients (Chan et al., 2003). Nursing home placement determines a significant increase in the overall cost of dementia care in addition to other direct and indirect costs associated with BPSD (Beeri et al., 2002; Herrmann et al., 2006). Psychotic symptoms (e.g., delusions) and disruptive behaviors (e.g., aggression, screaming) have been reported to be the most burdensome to caregivers (Miyamoto et al., 2010; Rocca et al., 
2010; Huang et al., 2011). In addition to BPSD, certain characteristics of caregivers are known to determine the risk of burden including overload, quality of the relationship with the patient, adverse life events, gender, level of neuroticism, role captivity, and levels of confidence (Campbell et al., 2008).

In MCI subjects, comorbid neuropsychiatric symptoms have been associated with worse cognitive performance, mild extrapyramidal signs, and functional disability (Monastero et al., 2009). Depressive symptoms in subjects with MCI have also been linked to progression to dementia (Modrego and Ferrández, 2004; Gabryelewicz et al., 2007) and increased brain atrophy over 2 years (Lee et al., 2012) suggesting that they may represent an early sign of a neurodegenerative disease.

\section{SYMPTOMS INTERRELATION AND EVOLUTION}

The unitary concept of BPSD encompassing the full range of emotional, psychological, and behavioral abnormalities occurring in dementia reflects the clinical heterogeneity and complexity of the symptoms and the difficulty in characterizing more specific subsyndromes or proprieties clusters co-varying during the course of the disease. Several studies have tried to identify neuropsychiatric sub-syndromes by grouping a number of individual symptoms which contingently co-occur during the course of dementia (Table 1). Ultimately, the recognition of discrete clinical entities is important to disclose underlying causal mechanisms and to develop etiological-based therapeutic interventions, even if the precise delineation of each syndrome remains elusive.

Although these studies differ in respect to study designs, assessment tools, and the size of samples, there is also a degree of concordance between the neuropsychiatric syndromes found (Table 1). Thus, delusions and hallucinations have been consistently grouped in a "psychosis" sub-syndrome in all factor analytical studies using the NPI. A distinct "mood" or "affective" cluster (depression and anxiety) has been reported by some studies (Aalten et al., 2007; Zuidema et al., 2007; Dechamps et al., 2008; Savva et al., 2009; Kang et al., 2010; Spalletta et al., 2010), while these symptoms have been included in different sub-syndromes by other authors (e.g., psychosis, agitation; Fuh et al., 2001; Mirakhur et al., 2004). A less reliable factor characterized by high levels of agitation, aggression, and aberrant motor behavior has emerged in several studies under various names (e.g., agitation, hyperactivity, frontal) (Frisoni et al., 1999; Aalten et al., 2003) presenting with heterogeneous psychopathological structure and suggesting that psychomotor features cooccur with psychotic and/or affective symptoms. There is evidence that "psychosis," "affective," and "agitation/aggression" factors remain stable across a 31-month period (Selbæk and Engedal, 2012).

The debate about the definition of the several psychiatric and behavioral symptoms in dementia continues as a number of symptoms (apathy, sleep, and eating disturbances) have not been grouped consistently across studies. Particularly, the relation between apathy (highly prevalent in dementia) and the "mood" sub-syndrome remains unclear. Studies conducted on outpatients (Aalten et al., 2008; Spalletta et al., 2010) and in nursing-homes (Zuidema et al., 2007; Dechamps et al., 2008; Selbæk and Engedal, 2012) support that apathy and depression are distinct phenomena and belong to different neuropsychiatric syndromes. However, other studies group both symptoms in the same factor (Frisoni et al., 1999; Aalten et al., 2003; Hollingworth et al., 2006).

These discrepancies may result from the fact that individual symptoms evolve differently over the course of dementia. For example, as shown by a large cross-sectional study involving 3404 subjects, while apathy increases linearly with cognitive decline, the relations between BPSD and level of cognitive impairment are non-linear with higher prevalence rates observed in the middle stages of dementia (Lövheim et al., 2008). Several other cross-sectional studies in both community and institutionalized populations reported that greater cognitive impairment or dementia severity is associated with higher rates of some BPSD (Table 2). Yet, other studies were in disagreement with these findings and a systematic review found a lack of association between the severity of dementia and the prevalence of depressive symptoms or diagnosed depression (Verkaik et al., 2007). Psychotic (Scarmeas et al., 2005; Emanuel et al., 2011) and depressive symptoms (Chan et al., 2011) were reported to predict a faster cognitive deterioration.

There is limited information about the natural history and course of neuropsychiatric symptoms in MCI. In this context, Ryu et al. (2011) have concluded that neuropsychiatric symptoms in MCI usually persist, with a significant percentage of patients having at least one persistent symptom. These symptoms were more severe at baseline (Ryu et al., 2011). On the other hand, the presence of specific symptoms can aggravate cognitive decline; patients who present with both amnestic-MCI and apathy, but not those with depression, had an almost seven-fold risk of AD progression compared to amnestic-MCI patients without apathy, after adjustment of variables (Palmer et al., 2010).

Longitudinal studies provided further insight into the evolution of BPDS during the course of the disease (Table 3 ). In the Maastricht Study of Behavior in Dementia (MAASBED) patients with mild dementia at baseline showed more neuropsychiatric symptoms, whereas patients with severe dementia showed fewer neuropsychiatric symptoms throughout 2 years (Aalten et al., 2005b). Overall, BPSD tend to be present chronically and most patients with baseline symptoms continue to show at least one symptom at subsequent assessments. In the population-based Cache County Study, 67\% of dementia subjects with clinically significant symptoms presented at least one symptom both at baseline and at 18 months follow-up assessment, with delusions and depression being the most persistent (Steinberg et al., 2004). In the MAASBED study $65 \%$ of outpatients who had a clinically relevant NPI total score at baseline continued to experience problems during the 2-year study period, with the most persistent symptoms being apathy and aberrant motor behavior (Aalten et al., 2005a). Persistence rates over 16 months were highest for delusions, agitation, depression, disinhibition, irritability, and aberrant motor behavior in a study conducted in nursing homes (Bergh et al., 2011). Repeated assessments have clarified that individual symptoms have an intermittent course, with elevated resolution and incidence rates throughout the time. Thus, one-third of patients with delusions, hallucinations, disinhibition, and agitation were symptom-free in the following 4 months (Bergh et al., 2011). Although it appears that BPSD have a heterogeneous pattern during the course of dementia, it has been proposed, especially in 
Table 1 | Neuropsychiatric sub-syndromes reported in patients with dementia.

\begin{tabular}{|c|c|c|}
\hline Reference & Sample/methods & Clusters \\
\hline Devanand et al. (1992) & $\begin{array}{l}106 \text { AD patients (outpatient } \\
\text { clinic) BSSD }\end{array}$ & $\begin{array}{l}\text { Disinhibition } \\
\text { Apathy-indifference } \\
\text { Dependency motor agitation } \\
\text { Self-destructive behaviors }\end{array}$ \\
\hline Hope et al. (1997) & $\begin{array}{l}97 \mathrm{AD} \text { or VaD patients } \\
\text { (community) } \\
\text { PBE, PCA }\end{array}$ & $\begin{array}{l}\text { Overactivity: walking more, aimless walking, trailing or checking } \\
\text { Aggressive behavior: aggressive resistance, physical aggression, verbal aggression and hos- } \\
\text { tility } \\
\text { Psychosis: hallucinations, persecutory ideas, anxiety }\end{array}$ \\
\hline Harwood et al. (1998) & $\begin{array}{l}151 \text { AD patients (outpatient } \\
\text { clinic) } \\
\text { BEHAVE-AD, PCA }\end{array}$ & $\begin{array}{l}\text { Agitation/anxiety: agitation, anxiety of upcoming events, other anxiety } \\
\text { Psychosis: delusions of theft, suspiciousness/paranoia, visual hallucinations } \\
\text { Aggression: verbal aggression, physical treats/violence, fear of being left alone, other delu- } \\
\text { sions } \\
\text { Depression: tearfulness, depressed mood } \\
\text { Activity disturbance: wandering, delusion one's house is not one's home }\end{array}$ \\
\hline Frisoni et al. (1999) & $\begin{array}{l}162 \text { AD patients (hospital) } \\
\text { NPI, PCA }\end{array}$ & $\begin{array}{l}\text { Mood syndrome } \\
\text { Psychosis syndrome } \\
\text { Frontal syndrome }\end{array}$ \\
\hline Fuh et al. (2001) & $\begin{array}{l}320 \mathrm{AD}+212 \mathrm{VaD} \text { patients } \\
\text { (outpatient clinic) } \\
\text { NPI, FA }\end{array}$ & $\begin{array}{l}\text { Mood and psychosis } \\
\text { Psychomotor regulation } \\
\text { Social engagement }\end{array}$ \\
\hline Lyketsos et al. (2001) & $\begin{array}{l}198 \text { AD patients (community) } \\
\text { NPI, LCA }\end{array}$ & $\begin{array}{l}\text { Minimally symptomatic } \\
\text { Affective disturbance (depression, irritability, anxiety euphoria) } \\
\text { Psychotic disturbance (delusions, hallucinations) }\end{array}$ \\
\hline Schreinzer et al. (2005) & $\begin{array}{l}133 \text { dementia patients } \\
\text { (chronic care hospital) } \\
\text { BEHAVE-AD, PCA }\end{array}$ & $\begin{array}{l}\text { Agitation } \\
\text { Affective disturbance } \\
\text { Altered circadian rhythms }\end{array}$ \\
\hline Matsui et al. (2006) & $\begin{array}{l}140 \text { AD patients (outpatient } \\
\text { clinic) } \\
\text { NPI, FA }\end{array}$ & $\begin{array}{l}\text { Psychosis: delusions, hallucinations, anxiety, agitation, disinhibition, irritability, aberrant } \\
\text { motor activity } \\
\text { Mood: apathy, depression/euphoria } \\
\text { Euphoria: euphoria }\end{array}$ \\
\hline Hollingworth et al. (2006) & $\begin{array}{l}1120 \text { AD patients } \\
\text { (community + nursing homes) } \\
\text { NPI, PCA }\end{array}$ & $\begin{array}{l}\text { Behavioral dyscontrol: euphoria, disinhibition, aberrant motor behavior, sleep, appetite } \\
\text { Psychosis: delusions, hallucinations } \\
\text { Mood: depression, anxiety, apathy } \\
\text { Agitation: irritability, aggression }\end{array}$ \\
\hline $\begin{array}{l}\text { Aalten et al. (2007) } \\
\text { Aalten et al. (2008) }\end{array}$ & $\begin{array}{l}\text { 2354/2808 AD patients } \\
\text { (outpatient clinic) } \\
\text { NPI, PCA }\end{array}$ & $\begin{array}{l}\text { Hyperactivity: agitation; euphoria; disinhibition; irritability; aberrant motor behavior Psy- } \\
\text { chosis: delusions; hallucinations; night time behavior disturbance } \\
\text { Affective symptoms: depression; anxiety } \\
\text { Apathy: apathy; appetite/eating abnormalities }\end{array}$ \\
\hline
\end{tabular}


Table 1 | Continued

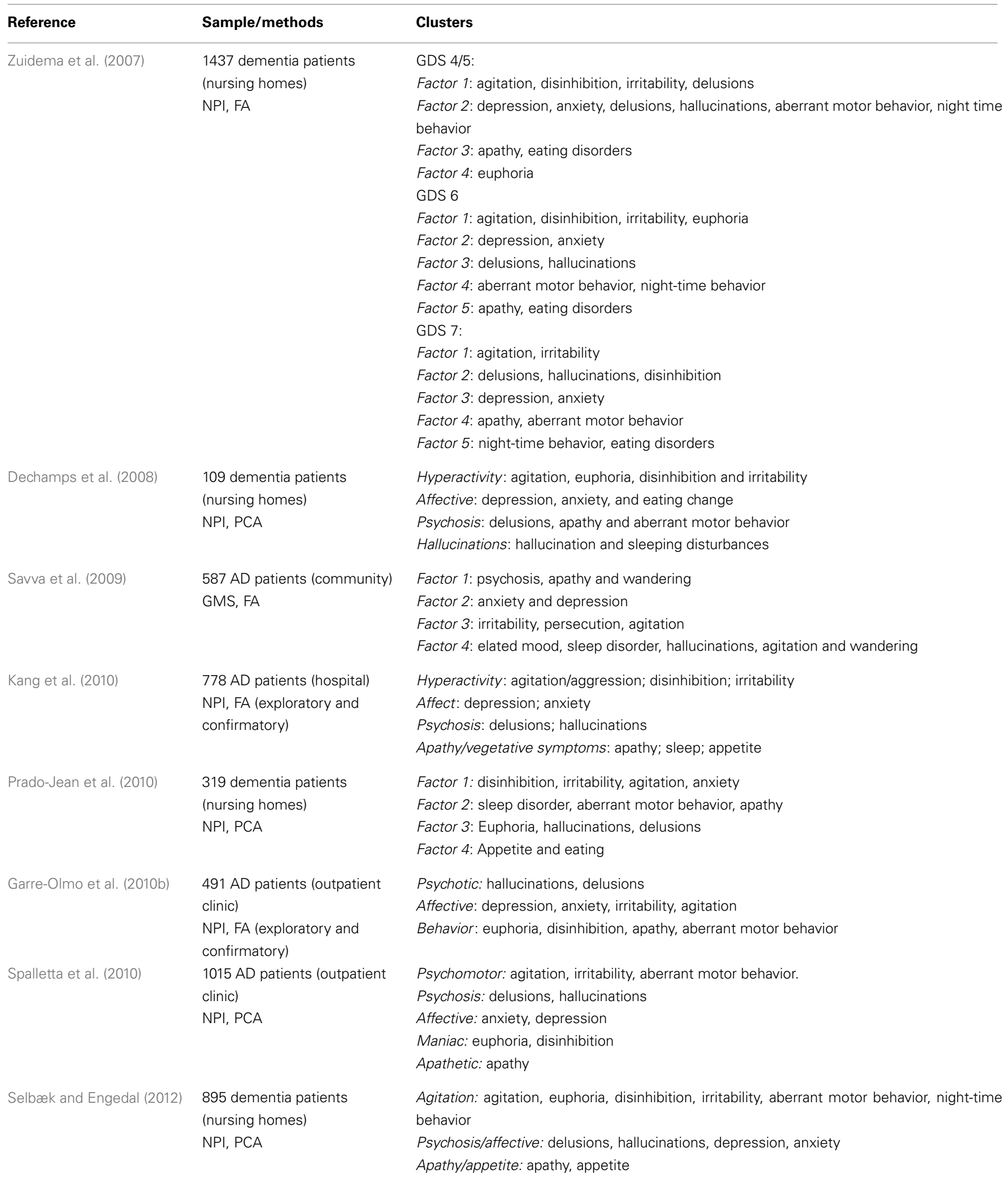

$A D$, Alzheimer disease; BSSD, behavioral syndromes scale for dementia; GMS, geriatric mental state; LCA, latent class analysis; NPI, neuropsychiatric inventory; $\mathrm{NPI-NH}$, neuropsychiatric inventory-nursing home version; PBE, present behavioral examination; PCA, principal component analysis; VaD, vascular dementia. 
Table 2 | BPSD and dementia severity: cross-sectional studies.

\begin{tabular}{lll}
\hline Reference & Sample & Findings \\
\hline Aalten et al. (2008) & $\begin{array}{l}2808 \text { AD patients (outpatient } \\
\text { clinic) }\end{array}$ & $\begin{array}{l}\text { Psychosis and hyperactivity co-occurred more often in more severe stages } \\
\text { of dementia. }\end{array}$ \\
Cheng et al. (2009) & $\begin{array}{l}138 \text { (outpatient clinic) }+173 \\
\text { (long-term care) AD patients }\end{array}$ & $\begin{array}{l}\text { Severity of delusion/paranoid ideation, hallucination, activity disturbances, } \\
\text { aggressiveness, diurnal rhythm disturbance and behavioral problems } \\
\text { significantly associated with severity of dementia. }\end{array}$
\end{tabular}

Craig et al. (2005) 435 AD patients (hospital)

Di lulio et al. (2010)

Fernández Martínez et al. (2008a)

Fernández Martínez et al. (2008b)

Fernandez-Martinez et al. (2010)

Fuh et al. (2005)

García-Alberca et al. (2010)

Geda et al. (2004)

Lopez et al. (2003)

Lövheim et al. (2008)

Lyketsos et al. (2000)

Matsui et al. (2006)

Spalletta et al. (2010)

Thompson et al. (2010)
$119 A D+68$

multidomain- $\mathrm{MCl}+58$

amnestic- $\mathrm{MCl}+107$ controls

$37 \mathrm{AD}+28 \mathrm{VaD}$ patients (hospital, outpatient clinic)

$81 \mathrm{AD}+14 \mathrm{VaD}+10$ PLBD + 3FTD (community)

$344 \mathrm{AD}+91 \mathrm{MCl}+50$ controls (hospital, outpatient clinic)

$320 \mathrm{AD}+212 \mathrm{VaD}$ patients (hospital, outpatient clinic)

125 AD patients (outpatient clinic)

$87 \mathrm{AD}+54 \mathrm{MCl}+514$ controls

1155 AD patients

3040 residents in geriatric care centers

329 dementia patients (community)

140 AD patients (outpatient clinic)

1015 AD patients (outpatient clinic)

$377 \mathrm{AD}+74 \mathrm{VaD}$ patients (outpatient clinic)
Depression/dysphoria and apathy/indifference more frequent in less severe dementia; hallucinations, elation/euphoria, and aberrant motor behavior more frequent in severe dementia. Apathy was the most persistent symptom; psychotic symptoms, delusions, and hallucinations exhibited the most rapid disappearance over time.

Apathy more prevalent with increasing severity of cognitive syndromes (amnestic-MCl to multidomain- $\mathrm{MCl}$, to $\mathrm{AD}$ ). Depression prevalence increased from amnestic- $\mathrm{MCl}$ to multidomain- $\mathrm{MCl}$, but not with dementia. No association with night-time disturbances.

Behavioral changes without correlation with severity of dementia in AD. Severity of delusions, hallucinations, aggression, irritability, aberrant motor behavior, night-time behavior and appetite changes correlated to cognitive decline in $\mathrm{VaD}$.

Prevalence of neuropsychiatric symptoms increased with dementia severity, but was not statistically significant.

All behavioral disorders increased with cognitive impairment, except for sleep and appetite disorders.

Delusions, hallucinations, and aberrant motor activities more common in later stages in both $A D$ and subcortical VaD.

No predictive value for MMSE in BPSD.

Total NPI scores significantly different among the 3 groups.

Psychiatric symptoms, except major depression, more frequent in more severe stages of the dementia.

Higher prevalence rates of BPSD in the middle stages of dementia. Passiveness increased linearly with the severity of cognitive impairment.

Severity of dementia associated with increased prevalence of agitation/aggression (13\% in mild dementia, $24 \%$ in moderate dementia, and $29 \%$ in severe dementia) and aberrant motor behavior (9\% in mild, $17 \%$ in moderate, and $19 \%$ in severe dementia).

Psychosis and agitated behaviors co-occurred with dementia progression.

Poor association between cognitive deficits and severity of BPSD symptoms.

Association between severity of BPSD and severity of dementia 


\section{Table 2 | Continued}

\begin{tabular}{lll}
\hline Reference & Sample & Findings \\
\hline Youn et al. (2011) & $\begin{array}{l}216 \text { AD patients (hospital, } \\
\text { outpatient clinic) }\end{array}$ & $\begin{array}{l}\text { Neuropsychiatric symptoms more frequent in moderate-to-severe stages } \\
\text { of AD, except loss of enjoyment and social withdrawal (more frequent in } \\
\text { mild stages). Frequencies of all neuropsychiatric syndromes significantly } \\
\end{array}$ \\
& $\begin{array}{l}\text { different in relation to the severity of disease, except for vegetative } \\
\text { suidema et al. (2010) }\end{array}$ & Dementia severity predicted physically aggressive behavior and apathy, \\
& (nursing homes) & with higher prevalence in more severe stages of dementia.
\end{tabular}

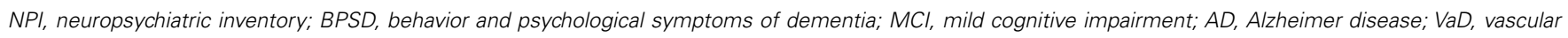
dementia; RAVLT, Rey auditory verbal learning test; TMT, trail-making test; MMSE, mini mental state examination; PLBD, Parkinson-Lewy body dementia.

$\mathrm{AD}$, that distinct groups of patients can be identified based on progressive changes in the frequency and severity of their BPSD (Garre-Olmo et al., 2010c).

In conclusion, instead of being independent phenomena, BPSD occur in a psychopathological pattern partially resembling primary psychiatric disorders, supporting a syndrome approach to their study and management. However, the psychopathological profile of each sub-syndrome is highly variable across patients (Savva et al., 2009). Also, the co-occurrence of sub-syndromes is common reflecting the complex and multi-level interaction between each BPSD (Dechamps et al., 2008) and supporting a personalized approach to each patient.

\section{ALZHEIMER'S DISEASE VS. OTHER DEMENTIA TYPES}

Although the manifestations of BPSD may be influenced by a variety of factors, they are primarily the result of the ongoing pathophysiological brain changes. It would be reasonable to assume that, as with the clinical and neuropsychological features, different profiles of neuropsychiatric symptoms could emerge in each sub-type of dementia, even at early stages. Thus, a higher prevalence of hallucinations and sleep disorders has been reported in non-amnestic-MCI, more likely to progress to non-AD dementia, in comparison to amnestic-MCI (Rozzini et al., 2008). However, studies comparing the profile of BPSD in AD and nonAlzheimer dementia have not yielded entirely uniform results (Tables 4 and 5).

\section{ALZHEIMER DISEASE VS. VASCULAR DEMENTIA}

The most consistent finding from the studies comparing vascular dementia $(\mathrm{VaD})$ with $\mathrm{AD}$ is a higher prevalence and severity of depression and anxiety, similar rates of psychotic symptoms, and less severe aberrant motor behavior among subjects with $\mathrm{VaD}$, although a substantial overlap can exist between the two dementia syndromes (Table 4). Similarly, the type of underlying vascular disease seems to determine a different clinical profile in $\mathrm{VaD}$ as apathy, aberrant motor behavior, and hallucinations have been associated with small-vessel $\mathrm{VaD}$, whereas euphoria and agitation/aggression were more severe among patients with large-vessel VaD (Staekenborg et al., 2010).

\section{ALZHEIMER DISEASE VS. DEMENTIA WITH LEWY BODIES}

Studies comparing the clinical profile of autopsy-confirmed cases of DLB and AD have consistently found a higher prevalence of delusions (misidentification, theft) and hallucinations (usually visual) in DLB patients independently of gender, ethnicity, and degree of cognitive impairment (Rockwell et al., 2000). These symptoms occur in up to 80 and $60 \%$ of patients respectively and tend to be more persistent over the course of the disease compared with AD patients (Ballard et al., 2001; Chiu et al., 2006; Stavitsky et al., 2006).

\section{ALZHEIMER DISEASE VS. FRONTO-TEMPORAL LOBAR DEGENERATION}

Fronto-temporal lobar degeneration (FTLD) is the prototype of a neurodegenerative disorder where changes in behavior, rather than in cognitive function, are the presenting feature and dominate the clinical picture throughout the disease course. The clinical spectrum of FTLD encompasses three distinct syndromes. The most common fronto-temporal dementia (also known as behavioral variant of fronto-temporal dementia) presents with a dramatic change in personal and social behavior. Early changes in language function are observed in semantic dementia and primary progressive non-fluent aphasia (Neary et al., 2005). Stereotypic behavior, appetite changes, and loss of social awareness are characteristic of FTLD with complex ritualized behaviors occurring more frequently in patients with fronto-temporal and semantic dementia than in AD (Bozeat et al., 2000; Ikeda et al., 2002). In contrast, simpler verbal stereotypes/perseveration or stimulus bound behavior, such as echolalia, seem to be equally common across the three groups (Nyatsanza et al., 2003). According to Bathgate et al. (2001) features that best discriminate FTLD from other dementias consist in loss of basic emotions, food cramming, pacing a fixed route, preserved capacity of locating objects, and impaired insight. Some behavioral features, such as lack of pain awareness, although not so common, provide diagnostic specificity as they are only rarely seen in other sub-types of dementia (Bathgate et al., 2001). Using the BEHAVE-AD scale, Chiu et al. (2006) found that AD outpatients presented with an increased incidence of anxiety and phobias $(61.2 \%)$ whereas subjects with fronto-temporal dementia had higher levels of activity disturbances (92.3\%).

\section{OTHER FACTORS ASSOCIATED WITH BPSD}

Besides the influence of dementia stage and subtype on the emergence of BPSD, other factors such as demographic variables and the use of medication have not been extensively explored. A number of associations, albeit not consistently replicated, 
Table 3 | BPSD evolution: longitudinal studies.

\begin{tabular}{|c|c|c|}
\hline Reference & Follow-up & Findings \\
\hline Aalten et al. (2005a) & $\begin{array}{l}2 \text { years (each } 6 \\
\text { months) }\end{array}$ & $\begin{array}{l}\text { No significant changes over time in the three sub-syndromes or in the NPI total score. } \\
\text { Depression became less common, persistent and severe with disease progression. Apathy } \\
\text { increased from the second visit (after six months), and persisted during the more advanced } \\
\text { stages of dementia. Psychosis (delusions) was most common in the moderate stages, showing } \\
\text { low persistence over time. }\end{array}$ \\
\hline Aalten et al. (2005b) & & $\begin{array}{l}\text { Mild dementia at baseline predicted increasing prevalence of NPS with time, whereas the } \\
\text { reverse was observed with severe dementia. Presence of NPI symptoms at baseline predicted } \\
\text { the subsequent development of symptoms (especially mood/apathy). Hyperactivity predicted } \\
\text { the development of psychosis but not vice-versa. }\end{array}$ \\
\hline Bergh et al. (2011) & $\begin{array}{l}16 \text { months (each } \\
4 \text { months) }\end{array}$ & $\begin{array}{l}\text { Highest cumulative incidence for irritability (42.6\%), disinhibition (37.8\%) and depression } \\
(31.5 \%) \text {. High persistence for Delusions, agitation, depression, disinhibition, irritability and } \\
\text { aberrant motor behavior. No significant change in the severity of the NPS during the follow-up } \\
\text { period. }\end{array}$ \\
\hline Garre-Olmo et al. (2010c) & 24-months & $\begin{array}{l}\text { Increase of psychotic and behavioral symptoms (18-26\% and } 63-72 \% \text {, respectively). Affective } \\
\text { symptoms remained stable over the follow-up. }\end{array}$ \\
\hline Savva et al. (2009) & 2 years & $\begin{array}{l}\text { Presence of apathy, elated mood or confabulation at follow-up was not significantly linked to } \\
\text { their presence at baseline. Conversely, anxiety, depression, and wandering behavior at baseline } \\
\text { were strong indicators for their presence at follow-up. Anxiety, depression, and elation did not } \\
\text { tend to persist. Symptoms of psychosis were more persistent. }\end{array}$ \\
\hline Selbaek et al. (2008) & 12-month & $\begin{array}{l}\text { Symptoms were chronically present, although individual symptoms often showed an intermittent } \\
\text { course with higher resolution for depression (58\%), delusions (56\%), and agitation/aggression } \\
(47 \%) \text {. }\end{array}$ \\
\hline Selbæk and Engedal (2012) & 31 months & $\begin{array}{l}\text { The most stable co-occurring symptoms in one and the same factor were depression and } \\
\text { anxiety (affective), agitation, irritability, and disinhibition (agitation), delusions and hallucinations } \\
\text { (psychosis), and apathy and appetite disorder. }\end{array}$ \\
\hline Serra et al. (2010b) & 12 months & $\begin{array}{l}\text { Frequency and severity of dysphoria/depression, apathy, agitation/aggression, and anxiety } \\
\text { remained substantially the same at follow-up. Delusions and irritability/lability increased } \\
\text { significantly. }\end{array}$ \\
\hline Steinberg et al. (2004) & 18 months & Delusions and depression were the most persistent, while disinhibition was the least. \\
\hline Tschanz et al. (2011) & $\begin{array}{l}3.8 \text { years } \\
\text { Drop-out: } 29 \%\end{array}$ & $\begin{array}{l}\text { Increasing occurrence, rate, and overall severity of NPS over time. Rate of change in NPS was } \\
\text { weakly correlated with rate of change in cognition or function. }\end{array}$ \\
\hline Wancata et al. (2003) & $\begin{array}{l}6 \text { months } \\
\text { Drop-out: } 26.9 \%\end{array}$ & $\begin{array}{l}\text { While, at } \mathrm{T} 1,33.7 \% \text { suffered from any marked or severe non-cognitive symptoms, } 11.6 \% \\
\text { remitted from these symptoms within } 6 \text { months. }\end{array}$ \\
\hline Weamer et al. (2009) & 2 years & $\begin{array}{l}\text { Greater global cognitive impairment was present at base line in subjects who developed } \\
\text { psychosis at follow-up. }\end{array}$ \\
\hline Wetzels et al. (2010) & 2 years & $\begin{array}{l}\text { Agitation, irritability, and aberrant motor behavior were the most prevalent over the } 2 \text { years. } \\
\text { Affective symptoms decreased, apathy tended to increase. Agitation and aberrant motor } \\
\text { behavior were the most persistent symptoms. }\end{array}$ \\
\hline
\end{tabular}

have been described between neuropsychiatric symptoms, and patient-related or environmental factors.

\section{PATIENT-RELATED FACTORS \\ Demographic factors}

Aggressiveness or aberrant motor behavior has been more frequently reported in men with dementia whereas female gender has been associated with depressive/anxious symptoms and verbally agitated help-seeking behavior (Lövheim et al., 2009; Zuidema et al., 2010; Karttunen et al., 2011). In one study, female elderly with $\mathrm{VaD}$ had more neuropsychiatric symptoms than male elderly (Hsieh et al., 2009). In other studies, age and gender did not influence the likelihood of BPSD manifestation in $\mathrm{AD}$ or $\mathrm{VaD}$ (Savva et al., 2009; Di Iulio et al., 2010; Staekenborg et al., 2010). 
Table 4 | BPSD: Alzheimer's disease vs. vascular dementia.

\begin{tabular}{|c|c|c|}
\hline Reference & Sample & Findings \\
\hline Aharon-Peretz et al. (2000) & $30 \mathrm{AD}+30 \mathrm{VaD}$ & Aggression, depression, anxiety and apathy significantly more severe in VaD-WSI than in AD. \\
\hline Ballard et al. (2000a) & $92 \mathrm{AD}+92 \mathrm{VaD}$ & $\begin{array}{l}\text { Depression and anxiety more common in } \mathrm{VaD} \text { than in } \mathrm{AD} \text {. Psychotic symptoms similarly } \\
\text { common in } \mathrm{VaD} \text { and in } \mathrm{AD} \text {. }\end{array}$ \\
\hline Chiu et al. (2006) & $85 \mathrm{AD}+32 \mathrm{VaD}$ & VaD with higher incidence of paranoid and delusional ideation and affective disturbance. \\
\hline Fernández Martínez et al. (2008a) & $37 \mathrm{AD}+28 \mathrm{VaD}$ & $\begin{array}{l}\text { Sleep disturbances and appetite changes more prevalent in } \mathrm{AD} \text { than in } \mathrm{VaD} \text {. Aberrant motor } \\
\text { activity more common in subcortical VaD. }\end{array}$ \\
\hline Fernández Martínez et al. (2008b) & $81 \mathrm{AD}+14 \mathrm{VaD}$ & Similar prevalence of BPSD in AD and $\mathrm{VaD}$. \\
\hline Fuh et al. (2005) & $320 \mathrm{AD}+212 \mathrm{VaD}$ & $\begin{array}{l}\text { Similar prevalence in } A D \text {, cortical VaD, sub-cortical VaD, and mixed VaD. More severe sleep } \\
\text { disturbance in cortical VaD than in } A D \text {. }\end{array}$ \\
\hline Hsieh et al. (2009) & $77 \mathrm{AD}+77 \mathrm{VaD}$ & $\begin{array}{l}\text { Higher prevalence of night-time behavior (sleep disturbance) in } A D \text {; higher prevalence of } \\
\text { depression in } \mathrm{VaD} \text {. Similar prevalence of delusions, hallucinations, and agitation in } A D \text { and } \mathrm{VaD}\end{array}$ \\
\hline Ikeda et al. (2004) & $21 \mathrm{AD}+28 \mathrm{VaD}$ & Delusions and aberrant motor behavior more likely in AD. \\
\hline Kim et al. (2003) & $99 \mathrm{AD}+36 \mathrm{VaD}$ & Depression and anxiety significantly more severe in $\mathrm{VaD}$ than in $\mathrm{AD}$. \\
\hline Lyketsos et al. (2000) & $214 \mathrm{AD}+62 \mathrm{VaD}$ & Delusions more likely in $A D$ and depression more frequent in VaD. \\
\hline Lyketsos et al. (2002) & 258 AD + 104 non-AD & $\begin{array}{l}\text { Similar prevalence in } A D \text { and non-AD dementia, except for more frequent aberrant motor } \\
\text { behavior in } A D \text {. }\end{array}$ \\
\hline Srikanth et al. (2005) & $44 \mathrm{AD}+31 \mathrm{VaD}$ & Similar symptom profile in AD and in VaD. \\
\hline Thompson et al. (2010) & $377 \mathrm{AD}+74 \mathrm{VaD}$ & No significant difference in $A D$ and $V a D$ patients on the BPCL or on the RMBPCL. \\
\hline
\end{tabular}

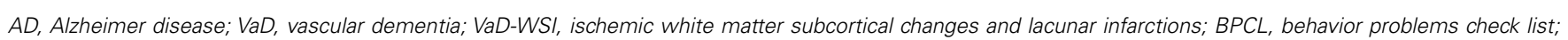
$R M B P C L$, revised memory and behavior problems check list.

Table 5 | BPSD: Alzheimer's disease vs. fronto-temporal lobar degeneration.

\begin{tabular}{|c|c|c|}
\hline Reference & Sample & Findings \\
\hline Bozeat et al. (2000) & $13 \mathrm{FTD}+20 \mathrm{SD}+37 \mathrm{AD}$ & $\begin{array}{l}\text { Stereotypic and eating behavior and loss of social awareness more common in the } \\
\text { FTD group. Mental rigidity and depression more frequent in SD than in FTD. Patients } \\
\text { with FTD more disinhibited. }\end{array}$ \\
\hline Chiu et al. (2006) & $17 \mathrm{FTD}+85 \mathrm{AD}+32 \mathrm{VaD}$ & Higher incidence of activity disturbances in FTD. \\
\hline Fernández Martínez et al. (2008b) & $3 \mathrm{FTD}+81 \mathrm{AD}+14 \mathrm{VaD}$ & Higher aberrant motor activity prevalence in FTD. \\
\hline Ikeda et al. (2002) & $23 \mathrm{FTD}+25 \mathrm{SD}+43 \mathrm{AD}$ & Changes in eating behaviors more common in both FTLD groups compared with AD. \\
\hline Levy et al. (1996) & $22 \mathrm{FTD}+30 \mathrm{AD}$ & $\begin{array}{l}\text { Higher scores for disinhibition, apathy, aberrant motor behavior, and euphoria in } \\
\text { patients with FTD compared with AD. }\end{array}$ \\
\hline Srikanth et al. (2005) & $23 \mathrm{FTLD}+44 \mathrm{AD}+31 \mathrm{VaD}$ & $\begin{array}{l}\text { Disinhibition, aberrant motor behavior, and appetite/eating disturbances could } \\
\text { reliably differentiate } A D \text { and } V a D \text { from FTLD. }\end{array}$ \\
\hline
\end{tabular}

$A D$, Alzheimer disease; FTLD, fronto-temporal lobar degeneration; FTD, fronto-temporal dementia; SD, semantic dementia. 
Considering that most studies included white population from northern European descent it's difficult to make assumptions about whether different symptom profile may arise according to ethnicity as reported by a few studies (Chen et al., 2000; Chow et al., 2002). In the study by Kim et al. (2003), age of onset and duration of dementia did not show any significant correlation with BPSD in patients with AD or VaD. Toyota et al. (2007) found conversely that early onset AD patients showed fewer BPSD than their late onset counterparts, particularly delusions, hallucinations, agitation, disinhibition, and aberrant motor behavior although this was not confirmed by a recent study (Garre-Olmo et al., 2010a).

\section{Psychotropic medication}

Aggressiveness and psychotic symptoms in outpatients with dementia have been found to increase the likelihood of receiving psychotropic medications by at least two-fold and this was coupled with a higher caregiver burden (Chiu et al., 2006). However, conclusions regarding the effects of medication on the natural course of BPSD are unclear as most studies don't have available data concerning the usual treatment of patients or don't include sub-analysis regarding this variable. Aalten et al. (2008) reported that the use of cholinesterase inhibitors (ChEI) influenced the structure of the apathy factor. Although this finding could derive from a therapeutic effect the available evidence suggests a modest impact of these drugs on neuropsychiatric symptoms (Rodda et al., 2009). The same holds true for antipsychotics which have been found to have little effect on the sub-syndrome factor structure of BPSD (Aalten et al., 2008).

\section{Psychopathological symptoms}

Depression affects up to $43 \%$ of patients with dementia and it predicts an increased number of neuropsychiatric symptoms, particularly agitation, anxiety, and irritability (Prado-Jean et al., 2010). Lack of insight occurs in the majority of AD patients even in early stages and appears to be an important predictive factor for the occurrence of increased levels of neuropsychiatric symptoms including apathy, agitation, irritability, psychosis, or behavioral symptoms in general (Vogel et al., 2010).

\section{Neuropsychological deficits}

The presence of alterations in specific cognitive domains may have a predictive value for the occurrence of BPSD. Psychotic symptoms in $\mathrm{AD}$ patients have been found to correlate with impairments in verbal fluency (Tsai et al., 2010) and in verbal learning tasks (Starr and Lonie, 2007). Premorbid IQ has been proposed to mediate the relationship between BPSDs and cognition in $\mathrm{AD}$ as it significantly correlated with mood, frontal, and psychotic factors (Starr and Lonie, 2007). In a cross-sectional study, impairments in memory (episodic and semantic), executive function, and verbal fluency all correlated with the severity of neuropsychiatric symptoms (García-Alberca et al., 2010). The presence of specific neurocognitive deficits, such as executive dysfunction, was reported to predict greater BPSD symptom severity in patients with MCI, particularly of depression and anxiety (Rosenberg et al., 2011).

\section{ENVIRONMENTAL FACTORS}

Presence of neuropsychiatric symptoms may arise from the characteristics of psychosocial/physical environment, such as crowded housing conditions leading to sensory overstimulation (for which patients with dementia are more susceptible), attitudes of care staff toward challenging behaviors and/or the size of the units in which patients reside throughout the day (Zuidema et al., 2010). Similarly, patients being restrained, or subjected to multiple moves and procedures, may also contribute to a range of BPSD symptoms, especially wandering and aggression (Kunik et al., 2010).

\section{PATHOPHYSIOLOGY AND NEUROBIOLOGY OF BPSD}

The behavioral or psychological disturbances occurring in dementia can be understood as ineffective attempts of the patient to cope with environmental or physiological stress factors. Indeed, BPSD are also common in non-demented older adults with rates of $5.6 \%$ for anxiety, $4.5 \%$ for irritability and $2.8 \%$ for agitation/aggression (Lyketsos et al., 2000) while psychotic symptoms are present in up to $10.5 \%$ of Swedish 85 years-old people (Ostling et al., 2009). It is important, therefore, to trace back these symptoms to premorbid psychosocial functioning which is determined by constitutional factors (e.g., personality traits, cognitive styles, and emotional reactivity), past experiences and level of education. Abnormalities in the intensity, magnitude, duration, timing, and modifiability of internal conditions and/or observable behaviors are expected to emerge beyond the limits of normal variability as the ongoing neuropathological changes of dementia undermine the individual's usual psychological capacities to adequately respond to everyday demands. Defining these neuroanatomical and neurochemical correlates of BPSD has been an area of active research with a hope that clarification of the underlying neurobiology will lead to more effective treatments (Tables 6-8).

\section{PSYCHOSIS}

Not many studies have examined the neuropathological correlates of psychosis in $\mathrm{AD}$. Two studies found an association of psychosis with increased severity of beta-amyloid senile plaques (SP) in the presubiculum (Zubenko et al., 1991) and across cortical regions (Mukaetova-Ladinska et al., 1995). Förstl et al. (1994) reported changes in neuronal counts in the CA1 hippocampus and parahippocampal gyrus, while Zubenko et al. (1991) described increased density of neurofibrillary tangles (NFT) in the middle frontal cortex. Furthermore, Farber et al. (2000) reported that AD patients with psychosis had a 2.3-fold greater density of neocortical NFTs than $\mathrm{AD}$ subjects devoid of psychotic symptomatology. However, no similar relation was observed in non-neocortical areas or with SP burden. On the other hand, no significant differences were found between $\mathrm{AD}$ patients with $(n=24)$ and without $(n=24)$ psychosis in respect to SP and NFT densities in the study by Sweet et al. (2000). Consistently with the neocortical role underlying psychotic symptomatology, AD subjects with psychosis demonstrated significant elevations of glycerophosphoethanolamine and significant reductions of $\mathrm{N}$-acetyl-L-aspartate in temporal, frontal, and parietal cortices (Sweet et al., 2002).

Neuroimaging studies have similarly confirmed severe abnormalities in grey matter volume, cerebral blood flow, and metabolism in the above cortical regions of $\mathrm{AD}$ subjects with psychotic symptoms (reviewed in Casanova et al., 2011). Anatomically, these changes partially coincide with cholinergic and dopaminergic pathways supporting, together with neurochemical and 
Table 6 | BPSD and structural changes in neuroimaging exams.

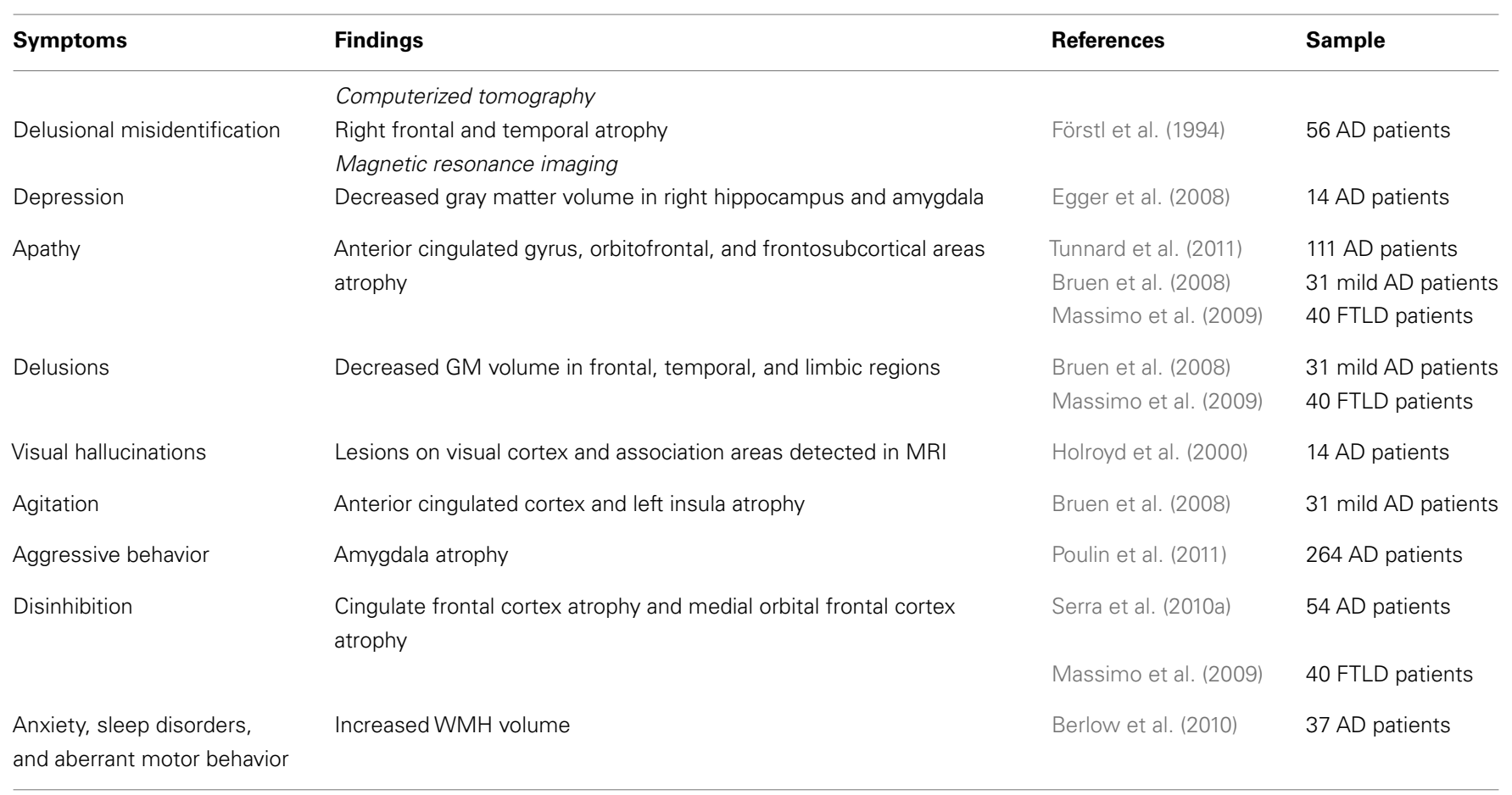

AD, Alzheimer disease; FTLD, fronto-temporal lobar degeneration; GM, gray matter; MRI, magnetic resonance imaging; WMH, white matter hyperintensities.

Table 7 | BPSD and functional changes in neuroimaging exams (PET and SPECT studies).

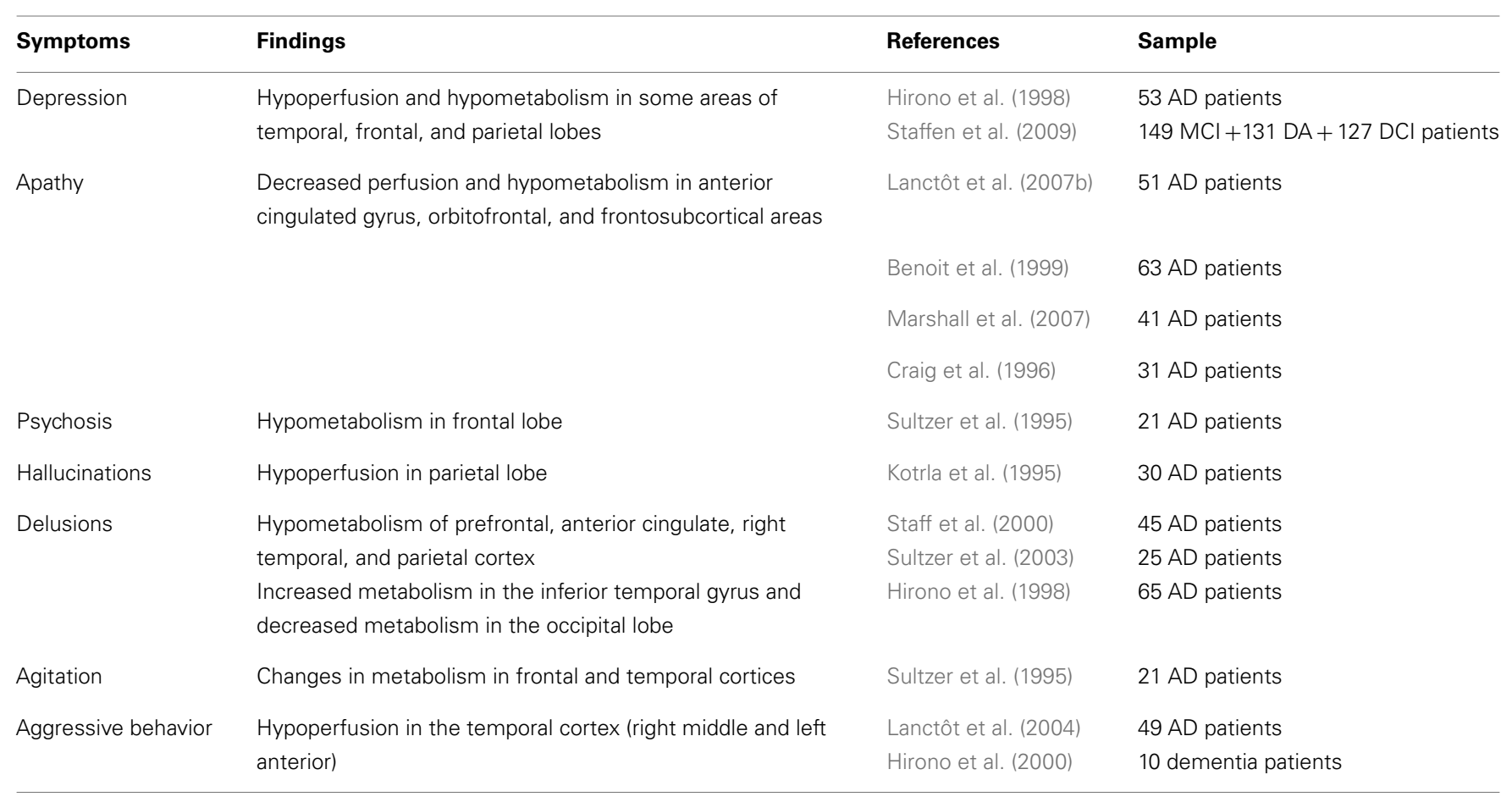

$A D$, Alzheimer disease; MCl, mild cognitive impairment; FTLD, fronto-temporal dementia; DCl, depression with cognitive impairment (DCI). 
Table 8 | Associations between BPSD and genes.

\begin{tabular}{|c|c|c|c|c|}
\hline References & Gene & Sample & Pathway & Clinical correlates \\
\hline \multirow[t]{3}{*}{ Borroni et al. (2006) } & COMT & 232 AD patients & Dopamine & $\begin{array}{l}\text { Higher risk for "psychosis" (ORs }=3.05,2.38 \text {, and } 1.80 \text { for } \\
\text { delusions, hallucinations, and sleep disturbance symptoms, } \\
\text { respectively) } p<0.05 \\
\text { Lower risk for "frontal" endophenotype (ORs }=0.25 \text { and } \\
0.25 \text { for disinhibition and euphoria, respectively). } P<0.05\end{array}$ \\
\hline & 5-HTTLPR & & Serotonin & $\begin{array}{l}\text { Lower risk for "psychosis" (ORs }=0.32,0.41 \text {, and } 0.54 \text { for } \\
\text { disinhibition and euphoria, respectively) }\end{array}$ \\
\hline & APOE4 & & & No correlation with any endophenotype \\
\hline Angelucci et al. (2009) & $\begin{array}{l}\text { 5-HT2A receptor } \\
\text { polymorphism }(102 \mathrm{~T} / \mathrm{C})\end{array}$ & $80 \mathrm{AD}$ patients & Serotonin & Delusions associated with T allele $(p<0.05)$ \\
\hline Di Maria et al. (2009) & G72 gene (locus DAO) & 185 AD patients & Glutamate & Delusions and hallucination $(p<0.05)$ \\
\hline \multirow[t]{5}{*}{ Proitsi et al. (2012) } & SERT STin2 12R & 1008 AD patients & Serotonin & Less "psychosis" ( $p=0.025)$ and less apathy $(p=0.007)$ \\
\hline & DAT 10R & & Dopamine & $\begin{array}{l}\text { Increased agitation }(p=0.003) \text { increased aberrant motor } \\
\text { behavior }(p=0.009)\end{array}$ \\
\hline & DRD4 2R & & & $\begin{array}{l}\text { Increased "moods" levels }(p=0.004) \text {; increased sleep } \\
\text { abnormalities }(p=0.032)\end{array}$ \\
\hline & DRD1 G & & & $\begin{array}{l}\text { Higher irritability }(p=0.01) \text {; lower aberrant motor behavior } \\
(p=0.023)\end{array}$ \\
\hline & DRD3 Ball C & & & Lower depression $(p=0.007)$ \\
\hline
\end{tabular}

COMT, catechol-O-methyl transferase; 5-HTTLPR, serotonin gene-linked polymorphic region; APOE, apolipoprotein E; 5-HT2A, serotonin 2A receptor; DAO, D-amino acid oxidase; SERT STin2, serotonin transporter gene polymorphism STin2; DAT, dopamine transporter gene; DRD4, dopamine receptor 4; DRD1, dopamine receptor 1; DRD3, dopamine receptor 3 Ball polymorphism.

pharmacological evidence, the role of acetylcholine and dopamine imbalance in the pathogenesis of $\mathrm{AD}$ psychosis (reviewed in Pinto et al., 2011). Psychosis has also been associated with the relative preservation of norepinephrine in the substantia nigra and a significant serotonin reduction in the presubiculum (Ismail et al., 2011). A strong hereditability has been reported for psychosis in $\mathrm{AD}$, suggesting an important role for APOE4 (Ismail et al., 2011). Other genes have also been associated with higher risk of psychosis [(COMT, G72 gene (locus DAO); 5-HT2A receptor polymorphism $(102 \mathrm{~T})$ ] while others may be "protective" (5-HTTLPR, SERT STin2 12R; Table 8). In DLB, visual hallucinations have been linked to higher Lewy Body density in the temporal cortex and amygdala (Harding et al., 2002; Tsuang et al., 2009) and with less severe density of neocortical tangles (Ballard et al., 2004). Cholinergic deficits have been described for hallucinations and delusions in both AD (Tsang et al., 2008) and DLB (Ballard et al., 2000b; Teaktong et al., 2005), thus providing a rationale for the therapeutic use of cholinergic drugs to treat these symptoms.

\section{DEPRESSION}

Several lines of evidence suggest that depression shares complex pathophysiological routes with dementia. It has been hypothesized that chronic depression may accelerate neurodegenerative changes of $\mathrm{AD}$ as a result of the neurotoxic effects of elevated cortisol levels in the hippocampus (Korczyn and Halperin, 2009). Moreover, the observation that the late-life depressive disorders are commonly associated with increased number of white matter hyperdensities in subcortical areas supported the so-called "vascular hypothesis" of depression (Alexopoulos, 2005). Reversely, neurodegenerative and vascular changes may act as a risk factor for depression.

Depressed non-demented patients present with chronic elevation of inflammatory mediators, known to play a central role in $\mathrm{AD}$ pathogenesis, together with altered serotonin metabolism and reduced neurotrophic activity (Caraci et al., 2010). So, in addition to being merely an emotional reaction to early memory deficits depression can be a prodromal symptom of dementia, a risk factor for neurodegeneration or co-occur with cognitive impairment. Post-mortem studies in $\mathrm{AD}$ subjects found higher burden of neuropathological lesions in those with a lifetime history of depression (Rapp et al., 2006) or presenting with concurrent depression (Rapp et al., 2008). Functional imaging studies revealed decreased perfusion and hypometabolism in the temporal, frontal, and parietal cortex, as well as in thalamus and lentiform nucleus of depressed compared to non-depressed AD patients (Hirono et al., 1998; Staffen et al., 2009). However, in other post-mortem studies in $\mathrm{AD}$ subjects with depressive symptoms were not related to the level of pathology (Wilson et al., 2003; Sweet et al., 2004).

The only prospective study assessing brain tissue from dementia-free subjects $(n=153)$ did not find increased AD or cerebrovascular pathology in those with late-life depression (Tsopelas et al., 2011), suggesting that depression per se may be linked to additional, more subtle neuropathological and/or neurobiochemical changes, such as those involving the neurotransmitter systems. Indeed, a disturbed serotoninergic system has been associated with depressive symptoms in $\mathrm{AD}$ as several areas of the brain exhibit decreased serotonin concentration, with a significant 
reduction in 5-HT1 and 5-HT2 receptors throughout the cerebral cortex (Lanari et al., 2006). Similarly, loss of noradrenergic cells in consequence of degeneration of the locus coeruleus is also seen in individuals with dementia who manifest depressive symptoms (Lanari et al., 2006). Changes of GABAergic plasma levels observed in final stages of $\mathrm{AD}$ have also been associated with depression, apathy, and aggressive behaviors (Lanctôt et al., 2007a). Association between genetic factors and depression are summarized in Table 8.

\section{APATHY}

Post-mortem and in vivo studies suggest that $\mathrm{AD}$ is associated with a dysfunctional dopaminergic system, since reduced levels of dopamine (DA) and homovanilic acid, as well as altered DA receptor density, have been described in discrete brain regions coinciding with the mesocorticolimbic pathway (Mitchell et al., 2011). On the other hand, neuroimaging studies in AD have been consistently showing a significant association between apathy and changes in the brain reward system including atrophy (Apostolova et al., 2007; Bruen et al., 2008; Tunnard et al., 2011), hypoperfusion and hypometabolism (Craig et al., 1996; Benoit et al., 1999; Lanctôt et al., 2007b; Marshall et al., 2007) in the anterior cingulated gyrus and orbitofrontal areas (Tables 6,7). It is also possible that dysfunction in these areas underlies the reported relation between increased frontal white matter changes and apathy (Starkstein et al., 2009) together with disruption of deep white matter afferents and efferents to the basal ganglia and/or by decrement of metabolic activity in frontal subcortical regions. In FTD subjects, apathy has been associated with atrophy in the anterior cingulated cortex, right dorso-lateral prefrontal cortex (Massimo et al., 2009), and adjacent medial frontal cortex (Rosen et al., 2005). This suggests that dysfunction in the frontosubcortical cingulate pathways is implicated in apathy regardless of the sub-type of dementia.

\section{OTHER SYMPTOMS}

Increased burden of NFT in the orbitofrontal cortex has been linked to agitation (Tekin et al., 2001), while aggressive behaviors have been associated with neuronal loss in locus ceruleus (Matthews et al., 2002). Deterioration of brainstem regions and in the suprachiasmatic nucleus of the hypothalamus has been reported in patients with sleep disorders (Yesavage et al., 2003).

\section{MANAGEMENT OF BPSD}

Management of BPSD is a key component of a comprehensive approach to the treatment of dementia requiring the judicious combination of pharmacological and non-pharmacological interventions. Treatment of these symptoms remains problematical, with an increased risk of psychotropic medication misuse, and, thus, represents an important challenge for clinicians. Current guidelines recommend non-pharmacological interventions as first-line treatment followed by the least harmful medication for the shortest time possible (Gauthier et al., 2010; Azermai et al., 2011).

\section{NON-PHARMACOLOGICAL INTERVENTIONS}

Non-pharmacological interventions have been classified into the following categories (O'Neil et al., 2011): (i) cognitive/emotionoriented interventions (reminiscence therapy, simulated presence therapy, validation therapy); (ii) sensory stimulation interventions (acupuncture, aromatherapy, light therapy, massage/touch, music therapy, Snoezelen multisensory stimulation, transcutaneous electrical nerve stimulation); (iii) behavior management techniques; and (iv) other psychosocial interventions such as animal-assisted therapy and exercise. Unfortunately, despite efforts in investigating these interventions, consistent evidence about the efficacy of the various psychosocial therapies is lacking (Kong et al., 2009). Benefits from psycho-educational interventions for caregivers were documented to be long-lasting, especially when delivered individually (Livingston et al., 2005). Special care units have been developed since the 1980s and are commonly situated in nursing homes. They include the features of trained staffing, a modified physical environment, and family involvement (Lai et al., 2009).

Specific therapeutic interventions for different symptoms of BPSD have also been investigated. In relation to agitation and aggressive behavior, and before opting for any intervention, it is important to carefully analyze the causes for the disruptive behavior: such causes may include pain, medical illness, fatigue, depression, loneliness, understimulation, or overstimulation; and social and environmental stressors (Iwata et al., 1993; Salzman et al., 2008). Strategies reported to be useful to reduce agitation include sensory interventions, particularly music therapy (Choi et al., 2009), aromatherapy (Ballard et al., 2009), and environmental modification (Weitzel et al., 2011). Regarding depression, recent studies support the effectiveness of home-based exercise programs for people with dementia and their caregivers to reduce depressive symptoms (Prick et al., 2011). Recently animal-assisted activities were suggested to be associated with a decrease in anxiety and sadness and an increase in positive emotions and motor activity (Mossello et al., 2011).

\section{PHARMACOLOGICAL INTERVENTIONS}

A variety of medications have been used to treat BPSD including typical and atypical antipsychotics, antidepressants, anticonvulsant mood stabilizers, ChEI, benzodiazepines, and other drugs, such as memantine. These drugs have variable efficacy and effectiveness in treating BPSD, depending on the target symptom and class of medication. The pharmacological treatment of BPSD should consider the presence of additional comorbidities and associated medications, which increase significantly the risk of both medical complications and drug interactions. Current guidelines recommend careful consideration of both benefits and limitations of each drug class with the use of the least harmful medication for the shortest time possible (Gauthier et al., 2010).

\section{Antipsychotics}

The use of antipsychotics, particularly since the introduction of atypical antipsychotics, has increased over time (Briesacher et al., 2005). They have shown efficacy in treating specific symptoms, such as aggression, psychosis, and agitation (Ballard et al., 2008; Gauthier et al., 2010). However the evidence regarding other BPSD symptoms is not convincing (Ballard et al., 2008). Despite serious side effects, including extrapyramidal symptoms, sedation, tardive dyskinesia, gait disturbances, falls, anticholinergic side effects, cerebrovascular events, and increased mortality, antipsychotic are 
still widely used off-label (Azermai et al., 2011). Risperidone, olanzapine, and haloperidol appear to be more effective for managing BPSD (Azermai et al., 2011). A recent study on dementia patients reported a 1.5 -fold increase in mortality associated with the use of haloperidol, compared to risperidone, olanzapine or quetiapine. The mortality risk with haloperidol was highest during the first 30 days and decreased significantly over time (Kales et al., 2012). The use of an antipsychotic for severe symptoms such as agitation, aggression, and psychotic symptoms should be timelimited and a careful individual evaluation is recommended due to increased risk of stroke and mortality. In the UK, risperidone is licensed for up to 6 weeks treatment of persistent aggression in subjects with moderate-to-severe $\mathrm{AD}$, and the recommendations are to be used as a last resort for aggression, when all other methods have failed to alleviate the most distressing symptoms of dementia, and only when it is in the best interests of the person (https://www.alzheimers.org.uk/antipsychotics). It is prudent to initiate with a low dose and regularly review the prescription in function of the patient's response and presence of adverse events.

\section{Antidepressants}

Antidepressants can be an effective and well-tolerated alternative to antipsychotics in vulnerable elderly individuals for treatment of BPSD (Henry et al., 2011). This class of drugs has been used primarily for depression, with efficacy especially for the selective serotonin reuptake inhibitors (SSRIs; Gauthier et al., 2010). Some authors found that citalopram and sertraline could improve symptoms of agitation and psychosis in subjects with dementia with similar efficacy, but better tolerability and safety, than haloperidol and risperidone (Gauthier et al., 2010; Seitz et al., 2011). Citalopram was effective in treating disinhibition, irritability and depression and also behaviors specific to FTD (Herrmann et al., 2011). However, the evidence so far does not support the use of these medications for BPSD other than depression (Azermai et al., 2011).

\section{Cholinergic inhibitors}

Current guidelines support the use of ChEI for BPSD although different recommendations exist to each specific drug (Gauthier et al., 2010). Donepezil, galantamine, or rivastigmine have all shown a modest effect on the broad spectrum of neuropsychiatric symptoms in AD (Rodda et al., 2009). They should be initiated prior to the use of other psychotropic agents since ChEIs reduce behavioral changes and improve or delay cognitive and functional decline (Gauthier et al., 2010). The behavioral symptoms most likely to improve with ChEIs treatment appear to be apathy, depression, and aberrant motor behavior (Cummings, 2004; Holmes et al., 2004; Feldman et al., 2005).

\section{Memantine}

Memantine, an NMDA receptor antagonist, can also have beneficial effects on behavior, as well as on cognition and function; however there is insufficient evidence to recommend its use (Azermai et al., 2011). The use of memantine appears to improve specific behaviors, such as agitation and irritability, which differ from those affected by ChEIs (mood symptoms, apathy, and aberrant motor behavior). Combination therapy may have advantages in patients with multiple BPSD (Gauthier et al., 2010). The latest report on combined memantine and ChEIs (donepezil) treatment did not show any major advantages on cognitive and behavioral changes in subjects with moderate-to-severe AD, compared to those treated with either memantine or donepezil, with only negligible improvement on the NPI scores in the subjects treated with the combination of the two antidementia drugs (Howard et al., 2012).

\section{Anticonvulsants}

Anticonvulsant mood stabilizers such as carbamazepine, valproic acid, gabapentin, lamotrigine, topiramate are widely used in clinical practice. Treatment regimens with anticonvulsant mood stabilizers have shown promising results and seem to be beneficial for some dementia patients (Konovalov et al., 2008). Anticonvulsants may allow dose reduction of antipsychotics; however, investigation regarding benefits, safety, and tolerability of these drugs has produced mixed results, so they are not recommended for routine use. In particular sodium valproate has been shown to be ineffective in the treatment of agitation in $\mathrm{AD}$, and has been associated with increased adverse effects, including falls, infection, and gastrointestinal disorders (Lonergan and Luxenberg, 2009).

\section{Benzodiazepines}

Benzodiazepines may be used at short-term for acute agitation or agitation associated with anxiety (Azermai et al., 2011).

\section{CONCLUSION}

Neuropsychiatric symptoms are frequent in dementia and contribute significantly for burden caregiver and illness costs. Correct identification and evaluation of these symptoms is a crucial part of the clinical approach to dementia. Despite the tentative efforts to group different symptoms into clusters (to facilitate clinical/diagnostic investigations), there is not yet an established model. The pathogenesis of these symptoms is not well understood, and the current knowledge supports multifactorial causes. Development and use of new specific investigation techniques may be helpful to better understand the underlying etiological mechanisms of various neuropsychiatric symptoms. At present, combination of non-pharmacological and appropriate pharmacological strategies represents the best treatment of BPSD. However, there is no consistent evidence about specific strategies for individual symptoms. It is necessary to encourage application of novel non-pharmacological interventions, which are safer than pharmacological therapies. Further investigation is similarly needed to find more effective, safe, and well-tolerated pharmacological therapies. This will help to devise novel, more symptom targeted, and specific interventions that will improve significantly the management of BPSD symptoms in subjects with dementia.

\section{ACKNOWLEDGMENTS}

We are grateful to Miss Maxine Berwick and Mrs. Carla Alves for secretarial support. 


\section{REFERENCES}

Aalten, P., de Vugt, M. E., Jaspers, N., Jolles, J., and Verhey, F. R. (2005a). The course of neuropsychiatric symptoms in dementia. Part I: findings from the two-year longitudinal Maasbed study. Int. J. Geriatr. Psychiatry 20, 523-530.

Aalten, P., de Vugt, M. E., Jaspers, N., Jolles, J., and Verhey, F. R. (2005b). The course of neuropsychiatric symptoms in dementia. Part II: relationships among behavioural sub-syndromes and the influence of clinical variables. Int. J. Geriatr. Psychiatry 20, 531-536.

Aalten, P., de Vugt, M. E., Lousberg, R., Korten, E., Jaspers, N., Senden, B., Jolles, J., and Verhey, F. R. (2003). Behavioral problems in dementia: a factor analysis of the neuropsychiatric inventory. Dement. Geriatr. Cogn. Disord. 15, 99-105.

Aalten, P., Verhey, F. R., Boziki, M., Brugnolo, A., Bullock, R., Byrne, E. J., Camus, V., Caputo, M., Collins, D., De Deyn, P. P., Elina, K., Frisoni, G., Holmes, C., Hurt, C., Marriott, A., Mecocci, P., Nobili, F., Ousset, P. J., Reynish, E., Salmon, E., Tsolaki, M., Vellas, B., and Robert, P. H. (2008). Consistency of neuropsychiatric syndromes across dementias: results from the European Alzheimer Disease Consortium. Part II. Dement. Geriatr. Cogn. Disord. 25, 1-8.

Aalten, P., Verhey Caputo, M., Collins, D., De Deyn, P. P., Elina, K., Frisoni, G., Girtler, N., Holmes, C., Hurt, C., Marriott, A., Mecocci, P., Nobili, F., Ousset, P. J., Reynish, E., Salmon, E., Tsolaki, M., Vellas, B., and Robert, P. H. (2007). Neuropsychiatric syndromes in dementia. Results from the European Alzheimer Disease Consortium: part I. Dement. Geriatr. Cogn. Disord. 24, 457-463.

Aharon-Peretz, J., Kliot, D., and Tomer, R. (2000). Behavioral differences between white matter lacunar dementia and Alzheimer's disease: a comparison on the neuropsychiatric inventory. Dement. Geriatr. Cogn. Disord. 11, 294-298.

Alexopoulos, G.S. (2005). Depression in the elderly. Lancet 365, 1961-1970.

American Psychiatric Association. (1994). Diagnostic and Statistical Manual of Mental Disorders, 4th Edn. Washington, DC: American Psychiatric Association.

Angelucci, F., Bernardini, S., Gravina, P., Bellincampi, L., Trequattrini, A., Di Iulio, F., Vanni, D., Federici, G., Caltagirone, C., Bossù, P., and Spalletta, G. (2009). Delusion symptoms and response to antipsychotic treatment are associated with the 5-HT2A receptor polymorphism (102T/C) in Alzheimer's disease: a 3-year followup longitudinal study. J. Alzheimers Dis. 17, 203-211.

Apostolova, L. G., Akopyan, G. G., Partiali, N., Steiner, C. A., Dutton, R. A., Hayashi, K. M., Dinov, I. D., Toga, A. W., Cummings, J. L., and Thompson, P. M. (2007). Structural correlates of apathy in Alzheimer's disease. Dement. Geriatr. Cogn. Disord. 24, 91-97.

Azermai, M., Petrovic, M., Elseviers, M. M., Bourgeois, J., Van Bortel, L. M., and Vander Stichele, R. H. (2011). Systematic appraisal of dementia guidelines for the management of behavioural and psychological symptoms. Ageing Res. Rev. 11, 78-86.

Ballard, C., Brown, R., Fossey, J., Douglas, S., Bradley, P., Hancock, J., James, I. A., Juszczak, E., Bentham, P., Burns, A., Lindesay, J., Jacoby, R., O’Brien, J., Bullock, R., Johnson, T., Holmes, C., and Howard, R. (2009). Brief psychosocial therapy for the treatment of agitation in Alzheimer disease (the CALM-AD trial). Am. J. Geriatr. Psychiatry 17, 726-733.

Ballard, C., Day, S., Sharp, S., Wing, G., and Sorensen, S. (2008). Neuropsychiatric symptoms in dementia: importance and treatment considerations. Int. Rev. Psychiatry 20, 396-404.

Ballard, C., Neill, D., O’Brien, J., McKeith, I. G., Ince, P., and Perry, R. (2000a). Anxiety, depression and psychosis in vascular dementia: prevalence and associations. J. Affect. Disord. 59, 97-106.

Ballard, C., Piggott, M., Johnson, M., Cairns, N., Perry, R., McKeith, I., Jaros, E., O'Brien, J., Holmes, C., and Perry, E. (2000b). Delusions associated with elevated muscarinic binding in dementia with Lewy bodies. Ann. Neurol. 48, 868-876.

Ballard, C., O’Brien, J., Gray, A., Cormack, F., Ayre, G., Rowan, E., Thompson, P., Bucks, R., McKeith, I., Walker, M., and Tovee, M. (2001). Attention and fluctuating attention in patients with dementia with Lewy bodies and Alzheimer disease. Arch. Neurol. 58, 977-982.

Ballard, C. G., Jacoby, R., Del Ser, T., Khan, M. N., Munoz, D. G., Holmes, C., Nagy, Z., Perry, E. K., Joachim, C., Jaros, E., O’Brien, J. T., Perry, R. H., and McKeith, I. G. (2004). Neuropathological substrates of psychiatric symptoms in prospectively studied patients with autopsy-confirmed dementia with
Lewy bodies. Am. J. Psychiatry 161, 843-849.

Bathgate, D., Snowden, J. S., Varma, A., Blackshaw, A., and Neary, D. (2001). Behaviour in frontotemporal dementia, Alzheimer's disease and vascular dementia. Acta Neurol. Scand. 103, 367-378.

Beeri, M. S., Werner, P., Davidson, M., and Noy, S. (2002). The cost of behavioral and psychological symptoms of dementia (BPSD) in community dwelling Alzheimer's disease patients. Int. J. Geriatr. Psychiatry 17, 403-408.

Benoit, M., Dygai, I., Migneco, O. Robert, P. H., Bertogliati, C., Darcourt, J., Benoliel, J., Aubin-Brunet, V., and Pringuey, D. (1999). Behavioral and psychological symptoms inAlzheimer's disease. Dement. Geriatr. Cogn. Disord. 10, 511-517.

Bergh, S., Engedal, K., Røen, I., and Selbæk, G. (2011). The course of neuropsychiatric symptoms in patients with dementia in Norwegian nursing homes. Int. Psychogeriatr. 23, 1231-1239.

Berlow, Y. A., Wells, W. M., Ellison, J. M., Sung, Y. H., Renshaw, P. F., and Harper, D. G. (2010). Neuropsychiatric correlates of white matter hyperintensities in Alzheimer's disease. Int. J. Geriatr. Psychiatry 25, 780-788.

Borroni, B., Grassi, M., Agosti, C., Costanzi, C., Archetti, S., Franzoni, S., Caltagirone, C., Di Luca, M., Caimi, L., and Padovani, A. (2006). Genetic correlates of behavioral endophenotypes in Alzheimer disease: role of COMT, 5-HTTLPR and APOE polymorphisms. Neurobiol. Aging 27, 1595-1603.

Bozeat, S., Gregory, C. A., Ralph, M. A., and Hodges, J. R. (2000). Which neuropsychiatric and behavioural features distinguish frontal and temporal variants of frontotemporal dementia from Alzheimer's disease? J. Neurol. Neurosurg. Psychiatr. 69, 178-186.

Briesacher, B. A., Limcangco, M. R., Simoni-Wastila, L., Doshi, J. A., Levens, S. R., Shea, D. G., and Stuart, B. (2005). The quality of antipsychotic drug prescribing in nursing homes. Arch. Intern. Med. 165, 1280-1285.

Bruen, P. D., McGeown, W. J., Shanks, M. F., and Venneri, A. (2008). Neuroanatomical correlates of neuropsychiatric symptoms in Alzheimer's disease. Brain $131(\mathrm{Pt}$ 9), 2455-2463.

Campbell, P., Wright, J., Oyebode, J., Job, D., Crome, P., Bentham, P., Jones, L., and Lendon, C. (2008). Determinants of burden in those who care for someone with dementia. Int. J. Geriatr. Psychiatry 23, 1078-1085.

Caraci, F., Copani, A., Nicoletti, F., and Drago, F. (2010). Depression and Alzheimer's disease: neurobiological links and common pharmacological targets. Eur. J. Pharmacol. 626, 64-71.

Casanova, M. F., Starkstein, S. E., and Jellinger, K. A. (2011). Clinicopathological correlates of behavioral and psychological symptoms of dementia. Acta Neuropathol. 122, 117-135.

Chan, D. C., Kasper, J. D., Black, B. S. and Rabins, P. V. (2003). Presence of behavioral and psychological symptoms predicts nursing home placement in community-dwelling elders with cognitive impairment in univariate but not multivariate analysis. J. Gerontol. A Biol. Sci. Med. Sci. 58, 548-554.

Chan, W. C., Lam, L. C., Tam, C. W., Lui, V. W., Leung, G. T., Lee, A, Chan, S. S., Fung, A. W., Chiu, H. F., and Chan, W. M. (2011). Neuropsychiatric symptoms are associated with increased risks of progression to dementia: a 2-year prospective study of 321 Chinese older persons with mild cognitive impairment. Age Ageing 40, 30-35.

Chen, J. C., Borson, S., and Scanlan, J. M. (2000). Stage-specific prevalence of behavioral symptoms in Alzheimer's disease in a multi-ethnic community sample. Am. J. Geriatr. Psychiatry 8, 123-133.

Cheng, T. W., Chen, T. F., Yip, P. K., Hua, M. S., Yang, C. C., and Chiu, M. J. (2009). Comparison of behavioral and psychological symptoms of Alzheimer's disease among institution residents and memory clinic outpatients. Int. Psychogeriatr. 21, 1134-1141.

Chiu, M. J., Chen, T. F., Yip, P. K. Hua, M. S., and Tang, L. Y. (2006) Behavioral and psychologic symptoms in different types of dementia. J. Formos. Med. Assoc. 105, 556-562. Choi, A. N., Lee, M. S., Cheong, K. J., and Lee, J. S. (2009). Effects of group music intervention on behavioral and psychological symptoms in patients with dementia: a pilotcontrolled trial. Int. J. Neurosci. 119, 471-481.

Chow, T. W., Liu, C. K., Fuh, J. L., Leung, V. P., Tai, C. T., Chen, L. W., Wang, S. J., Chiu, H. F., Lam, L. C., Chen, Q. L., and Cummings, J. L. (2002). Neuropsychiatric symptoms of Alzheimer's disease differ in Chinese and American patients. Int. J. Geriatr. Psychiatry 17, 22-28. 
Cohen-Mansfield, J. (1999). Measurement of inappropriate behavior associated with dementia. J. Gerontol. Nurs. 25, 42-51.

Cohen-Mansfield, J., Marx, M. S., Dakheel-Ali, M., Regier, N. G., Thein, K., and Freedman, L. (2010). Can agitated behavior of nursing home residents with dementia be prevented with the use of standardized stimuli? J. Am. Geriatr. Soc. 58, 1459-1464.

Craig, A. H., Cummings, J. L., Fairbanks, L., Itti, L., Miller, B., Li, J., and Mena, I. (1996). Cerebral blood flow correlates of apathy in Alzheimer disease. Arch. Neurol. 53, 1116-1120.

Craig, D., Mirakhur, A., Hart, D. J., McIlroy, S. P., and Passmore, A. P. (2005). A cross-sectional study of neuropsychiatric symptoms in 435 patients with Alzheimer's disease. Am. J. Geriatr. Psychiatry 13, 460-468.

Cummings, J. L. (1997). The neuropsychiatric inventory: assessing psychopathology in dementia patients. Neurology 48(5 Suppl. 6), S10-S16.

Cummings, J. L. (2004). Treatment of Alzheimer's disease: current and future therapeutic approaches. Rev. Neurol. Dis. 1, 60-69.

de Vugt, M. E., Stevens, F., Aalten, P., Lousberg, R., Jaspers, N., Winkens, I., Jolles, J., and Verhey, F. R. (2003). Behavioural disturbances in dementia patients and quality of the marital relationship. Int. J. Geriatr. Psychiatry 18, 149-154.

de Vugt, M. E., Stevens, F., Aalten, P., Lousberg, R., Jaspers, N., Winkens, I., Jolles, J., and Verhey, F. R. (2004). Do caregiver management strategies influence patient behaviour in dementia? Int. J. Geriatr. Psychiatry 19, 85-92.

Dechamps, A., Jutand, M. A., Onifade, C., Richard-Harston, S., and Bourdel-Marchasson, I. (2008). Cooccurrence of neuropsychiatric syndromes in demented and psychotic institutionalized elderly. Int. J. Geriatr. Psychiatry 23, 1182-1190.

Devanand, D. P., Brockington, C. D., Moody, B. J., Brown, R. P., Mayeux, R., Endicott, J., and Sackeim, H. A. (1992). Behavioral syndromes in Alzheimer's disease. Int. Psychogeriatr. 4(Suppl. 2), 161-184.

Di Iulio, F., Palmer, K., Blundo, C., Casini, A. R., Gianni, W., Caltagirone, C., and Spalletta, G. (2010). Occurrence of neuropsychiatric symptoms and psychiatric disorders in mild Alzheimer's disease and mild cognitive impairment subtypes. Int. Psychogeriatr. 22, 629-640.
Di Maria, E., Bonvicini, C., Bonomini, C., Alberici, A., Zanetti, O., and Gennarelli, M. (2009). Genetic variation in the G720/G30 gene locus (DAOA) influences the occurrence of psychotic symptoms in patients with Alzheimer's disease. J. Alzheimers Dis. 18, 953-960.

Egger, K., Schocke, M., Weiss, E., Auffinger, S., Esterhammer, R., Goebel Walch, T., Mechtcheriakov, S., and Marksteiner, J. (2008). Pattern of brain atrophy in elderly patients with depression revealed by voxelbased morphometry. Psychiatry Res. 164, 237-244.

Emanuel, J. E., Lopez, O. L., Houck, P. R., Becker, J. T., Weamer, E. A., Demichele-Sweet, M. A., Kuller, L., and Sweet, R. A. (2011). Trajectory of cognitive decline as a predictor of psychosis in early Alzheimer disease in the cardiovascular health study. Am. J. Geriatr. Psychiatry 19, 160-168.

Farber, N. B., Rubin, E. H., Newcomer, J. W., Kinscherf, D. A., Miller, J. P., Morris, J., Olney, J. W., and McKeel, D. W. Jr. (2000). Increased neocortical neurofibrillary tangle density in subjects with Alzheimer disease and psychosis. Arch. Gen. Psychiatry 57, 1165-1173.

Feldman, H., Gauthier, S., Hecker, J., Vellas, B., Xu, Y., Ieni, J. R., Schwam, E. M., and Donepezil MSAD Study Investigators Group. (2005). Donepezil MSAD Study Investigators Group. Efficacy and safety of donepezil in patients with more severe Alzheimer's disease: a subgroup analysis from a randomized, placebo-controlled trial. Int. J. Geriatr. Psychiatry 20, 559-569.

Fernández Martínez, M., Castro, J., Molano, A., Zarranz, J. J., Rodrigo, R. M., and Ortega, R. (2008a). Prevalence of neuropsychiatric symptoms in Alzheimer's disease and vascular dementia. Curr. Alzheimer Res. 5, 61-69.

Fernández Martínez, M., Castro Flores, J., Pérez de las Heras, S., Mandaluniz Lekumberri, A., Gordejuela Menocal, M., Zarranz Imirizaldu, J. J. (2008b). Prevalence of neuropsychiatric symptoms in elderly patients with dementia in Mungialde County (Basque Country, Spain). Dement. Geriatr. Cogn. Disord. 25, 103-108.

Fernandez-Martinez, M., Molano, A., Castro, J., and Zarranz, J. J. (2010). Prevalence of neuropsychiatric symptoms in mild cognitive impairment and Alzheimer's disease, and its relationship with cognitive impairment. Curr. Alzheimer Res. 7, 517-526.
Finkel, S. I., Costa e Silva, J., Cohen, G. Miller, S., and Sartorius, N. (1996). Behavioral and psychological signs and symptoms of dementia: a consensus statement on current knowledge and implications for research and treatment. Int. Psychogeriatr. 8(Suppl. 3), 497-500.

Förstl, H., Burns, A., Levy, R., and Cairns, N. (1994). Neuropathological correlates of psychotic phenomena in confirmed Alzheimer's disease. Br. J. Psychiatry 165, 53-59.

Frisoni, G. B., Rozzini, L., Gozzetti, A. Binetti, G., Zanetti, O., Bianchetti, A., Trabucchi, M., and Cummings, J. L. (1999). Behavioral syndromes in Alzheimer's disease: description and correlates. Dement. Geriatr. Cogn. Disord. 10, 130-138.

Fuh, J. L., Liu, C. K., Mega, M. S., Wang, S. J., and Cummings, J. L. (2001). Behavioral disorders and caregivers' reaction in Taiwanese patients with Alzheimer's disease. Int. Psychogeriatr. 13, 121-128.

Fuh, J. L., Wang, S. J., and Cummings, J. L. (2005). Neuropsychiatric profiles in patients with Alzheimer's disease and vascular dementia. J. Neurol. Neurosurg. Psychiatr. 76, 1337-1341.

Gabryelewicz, T., Styczynska, M., Luczywek, E., Barczak, A., Pfeffer, A., Androsiuk, W., Chodakowska-Zebrowska, M., Wasiak, B., Peplonska, B., and Barcikowska, M. (2007). The rate of conversion of mild cognitive impairment to dementia: predictive role of depression. Int. J. Geriatr. Psychiatry 22, 563-567.

García-Alberca, J. M., Lara Muñoz, J. P. and Berthier Torres, M. (2010). Neuropsychiatric and behavioral symptomatology in Alzheimer disease. Actas Esp. Psiquiatr. 38, 212-222.

Garre-Olmo, J., Genís Batlle, D., del Mar Fernández, M., Marquez Daniel, F., de Eugenio Huélamo, R., Casadevall, T., Turbau Recio, J., Turon Estrada, A., López-Pousa, S., and Registry of Dementia of Girona Study Group (ReDeGi Study Group). (2010a). Incidence and subtypes of earlyonset dementia in a geographically defined general population. Neurology 75, 1249-1255.

Garre-Olmo, J., López-Pousa, S., VilaltaFranch, J., de Gracia Blanco, M., and Vilarrasa, A. B. (2010b). Grouping and trajectories of the neuropsychiatric symptoms in patients with Alzheimer's disease, part I: symptom clusters. J. Alzheimers Dis. 22, 1157-1167.

Garre-Olmo, J., López-Pousa, S., Vilalta-Franch, J., de Gracia Blanco, M., and Vilarrasa, A. B. (2010c). Grouping and trajectories of neuropsychiatric symptoms in patients with Alzheimer's disease. Part II: two-year patient trajectories. J. Alzheimers Dis. 22, 1169-1180.

Gauthier, S., Cummings, J., Ballard, C., Brodaty, H., Grossberg, G., Robert, P., and Lyketsos, C. (2010). Management of behavioral problems in Alzheimer's disease. Int. Psychogeriatr. 22, 346-372.

Geda, Y. E., Smith, G. E., Knopman, D. S., Boeve, B. F., Tangalos, E. G., Ivnik, R. J., Mrazek, D. A., Edland, S. D., and Petersen, R. C. (2004). De novo genesis of neuropsychiatric symptoms in mild cognitive impairment (MCI). Int. Psychogeriatr. 16, 51-60.

Harding, A. J., Broe, G. A., and Halliday, G. M. (2002). Visual hallucinations in Lewy body disease. Relate to Lewy bodies in the temporal lobe. Brain 125(Pt 2), 391-403.

Harwood, D. G., Ownby, R. L., Barker, W. W., and Duara, R. (1998). The behavioral pathology in Alzheimer's disease scale (BEHAVE-AD): factor structure among communitydwelling Alzheimer's disease patients. Int. J. Geriatr. Psychiatry 13, 793-800.

Henry, G., Williamson, D., and Tampi, R. R. (2011). Efficacy and tolerability of antidepressants in the treatment of behavioral and psychological symptoms of dementia, a literature review of evidence. Am. J. Alzheimers Dis. Other Demen. 26, 169-183.

Herrmann, N., Black, S. E., Chow, T., Cappell, J., Tang-Wai, D. F., and Lanctôt, K. L. (2011). Serotonergic function and treatment of behavioral and psychological symptoms of frontotemporal dementia. Am. J. Geriatr. Psychiatry. doi: 10.1097/JGP.0b013e31823033f3. [Epub ahead of print].

Herrmann, N., Lanctôt, K. L., Sambrook, R., Lesnikova, N., Hébert, R., McCracken, P., Robillard, A., and Nguyen, E. (2006). The contribution of neuropsychiatric symptoms to the cost of dementia care. Int. J. Geriatr. Psychiatry 21, 972-976.

Hirono, N., Kitagaki, H., Kazui, H., Hashimoto, M., and Mori, E. (2000). Impact of white matter changes on clinical manifestation of Alzheimer's disease: a quantitative study. Stroke 31, 2182-2188.

Hirono, N., Mori, E., Ishii, K., Ikejiri, Y., Imamura, T., Shimomura, T., Hashimoto, M., Yamashita, H., and Sasaki, M. (1998). Frontal lobe hypometabolism and depression in Alzheimer's disease. Neurology 50, 380-383. 
Hollingworth, P., Hamshere, M. L., Moskvina, V., Dowzell, K., Moore, P. J., Foy, C., Archer, N., Lynch, A., Lovestone, S., Brayne, C., Rubinsztein, D. C., Lawlor, B., Gill, M., Owen, M. J., and Williams, J. (2006). Four components describe behavioral symptoms in 1,120 individuals with late-onset Alzheimer's disease. J. Am. Geriatr. Soc. 54, 1348-1354.

Holmes, C., Wilkinson, D., Dean, C., Vethanayagam, S., Olivieri, S., Langley, A., Pandita-Gunawardena, N. D., Hogg, F., Clare, C., and Damms, J. (2004). The efficacy of donepezil in the treatment of neuropsychiatric symptoms in Alzheimer disease. Neurology 63, 214-219.

Holroyd, S., Shepherd, M. L., and Downs, J. H. III. (2000). Occipital atrophy is associated with visual hallucinations in Alzheimer's disease. J. Neuropsychiatry Clin. Neurosci. 12, 25-28.

Hope, T., Keene, J., Fairburn, C., McShane, R., and Jacoby, R. (1997). Behaviour changes in dementia. 2: are there behavioural syndromes? Int. J. Geriatr. Psychiatry 12, 1074-1078.

Howard, R., McShane, R., Lindesay, J., Ritchie, C., Baldwin, A., Barber, R., Burns, A., Dening, T., Findlay, D., Holmes, C., Hughes, A., Jacoby, R., Jones, R., Jones, R., McKeith, I., Macharouthu, A., O'Brien, J., Passmore, P., Sheehan, B., Juszczak, E., Katona, C., Hills, R., Knapp, M., Ballard, C., Brown, R., Banerjee, S., Onions, C., Griffin, M., Adams, J., Gray, R., Johnson, T., Bentham, P., and Phillips, P.(2012). Donepezil and memantine for moderate-tosevere Alzheimer's disease. N. Engl. J. Med. 366, 893-903.

Hsieh, C. J., Chang, C. C., and Lin, C. C. (2009). Neuropsychiatric profiles of patients with Alzheimer's disease and vascular dementia in Taiwan. Int. J. Geriatr. Psychiatry 24, 570-577.

Huang, S. S., Lee, M. C., Liao, Y. C., Wang, W. F., and Lai, T. J. (2011). Caregiver burden associated with behavioral and psychological symptoms of dementia (BPSD) in Taiwanese elderly. Arch. Gerontol. Geriatr. doi: 10.1016/j.archger.2011.04.009. [Epub ahead of print].

Ikeda, M., Brown, J., Holland, A. J., Fukuhara, R., and Hodges, J. R. (2002). Changes in appetite, food preference, and eating habits in frontotemporal dementia and Alzheimer's disease. J. Neurol. Neurosurg. Psychiatr. 73, 371-376.
Ikeda, M., Fukuhara, R., Shigenobu, K., Hokoishi, K., Maki, N., Nebu, A., Komori, K., and Tanabe, H. (2004). Dementia associated mental and behavioural disturbances in elderly people in the community: findings from the first Nakayama study. J. Neurol. Neurosurg. Psychiatr. 75, 146-148.

Ismail, Z., Nguyen, M. Q., Fischer, C. E., Schweizer, T. A., Mulsant, B. H., and Mamo, D. (2011). Neurobiology of delusions in Alzheimer's disease. Curr. Psychiatry Rep. 13, 211-218.

Iwata, B. A., Volmer, T. R., and Zarcone, J. R. (1993). "The experimental (functional) analysis of behavioral disorders: methodology, application, and limitations," in Perspectives on the Use of Nonaversive and Aversive Interventions for Persons with Developmental Disabilities, eds A. C. Repp and N. N. Singh (Sycamore, IL: Sycamore Press), 301-330.

Jeste, D. V., Meeks, T. W., Kim, D. S., and Zubenko, G. S. (2006). Research agenda for DSM-V: diagnostic categories and criteria for neuropsychiatric syndromes in dementia. J. Geriatr. Psychiatry. Neurol. 19, 160-171.

Kales, H. C., Kim, H. M., Zivin, K., Valenstein, M., Seyfried, L. S., Chian, C., Cunningham, F., Schneider, L. S., and Blow, F. C. (2012). Risk of mortality among individual antipsychotics in patients with dementia. Am. J. Psychiatry 169, 71-79.

Kang, H. S., Ahn, I. S., Kim, J. H., and Kim, D. K. (2010). Neuropsychiatric symptoms in korean patient with Alzheimer's disease: exploratory factor analysis and confirmatory factor analysis of the neuropsychiatric inventory. Dement. Geriatr. Cogn. Disord. 29, 82-87.

Karlawish, J. H., Zbrozek, A., Kinosian, B., Gregory, A., Ferguson, A., Low, D. V., and Glick, H. A. (2008). Caregivers' assessments of preference-based quality of life in Alzheimer's disease. Alzheimers Dement. 4, 203-211.

Karttunen, K., Karppi, P., Hiltunen, A., Vanhanen, M., Välimäki, T., Martikaine Valtonen, H., Sivenius, J., Soininen, H., Hartikainen, S., Suhonen, J., Pirttilä, T., and ALSOVA study group. (2011). Neuropsychiatric symptoms and quality of life in patients with very mild and mild Alzheimer's disease. Int. J. Geriatr. Psychiatry 26, 473-482.

Katona, C., Livingston, G., Cooper, C., Ames, D., Brodaty, H., and Chiu, E. (2007). International Psychogeriatric Association consensus statement on defining and measuring treatment benefits in dementia. Int Psychogeriatr. 19, 345-354.

Kim, J. M., Lyons, D., Shin, I. S., and Yoon, J. S. (2003). Differences in the behavioral and psychological symptoms between Alzheimer's disease and vascular dementia: are the different pharmacologic treatment strategies justifiable? Hum. Psychopharmacol. 18, 215-220.

Kong, E. H., Evans, L. K., and Guevara, J. P. (2009). Nonpharmacological intervention for agitation in dementia: a systematic review and meta-analysis. Aging Ment. Health 13, 512-520.

Konovalov, S., Muralee, S., and Tampi, R. R. (2008). Anticonvulsants for the treatment of behavioral and psychological symptoms of dementia: a literature review. Int. Psychogeriatr. 20, 293-308.

Korczyn, A. D., and Halperin, I. (2009). Depression and dementia. J. Neurol. Sci. 283, 139-142.

Kotrla, K. J., Chacko, R. C., Harper, R. G., Jhingran, S., and Doody, R. (1995). SPECT findings on psychosis in Alzheimer's disease. Am. J. Psychiatry 152, 1470-1475.

Kunik, M. E., Snow, A. L., Davila, J. A., McNeese, T., Steele, A. B., Balasubramanyam, V., Doody, R., Schulz, P. E., Kalavar, J. S., Walder, A., and Morgan, R. O. (2010). Consequences of aggressive behavior in patients with dementia. J. Neuropsychiatry Clin. Neurosci. 22, 40-47.

Lai, C. K., Yeung, J. H., Mok, V., and Chi, I. (2009). Special care units for dementia individuals with behavioural problems. Cochrane Database Syst. Rev. 4, CD006470.

Lanari, A., Amenta, F., Silvestrelli, G., Tomassoni, D., and Parnetti, L. (2006). Neurotransmitter deficits in behavioural and psychological symptoms of Alzheimer's disease. Mech. Ageing Dev. 127, 158-165.

Lanctôt, K. L., Herrmann, N., Nadkarni, N. K., Leibovitch, F. S., Caldwell, C. B., and Black, S. E. (2004). Medial temporal hypoperfusion and aggression in Alzheimer disease. Arch. Neurol. 61, 1731-1737.

Lanctôt, K. L., Herrmann, N., Rothenburg, L., and Eryavec, G. (2007a). Behavioral correlates of GABAergic disruption in Alzheimer's disease. Int. Psychogeriatr. 19, 151-158.

Lanctôt, K. L., Moosa, S., Herrmann, N., Leibovitch, F. S., Rothenburg, L., Cotter, A., and Black, S. E. (2007b). A SPECT study of apathy in Alzheimer's disease. Dement. Geriatr. Cogn. Disord. 24, 65-72.

Lee, G. J., Lu, P. H., Hua, X., Lee, S., Wu, S., Nguyen, K., Teng,
E., Leow, A. D., Jack, C. R. Jr., Toga, A. W., Weiner, M. W., Bartzokis, G., Thompson, P. M., and Alzheimer's Disease Neuroimaging Initiative. (2012). Depressive symptoms in mild cognitive impairment predict greater atrophy in Alzheimer's disease-related regions. Biol. Psychiatry 71, 814-821.

Levy, M. L., Miller, B. L., Cummings, J. L., Fairbanks, L. A., and Craig, A. (1996). Alzheimer disease and frontotemporal dementias. Behavioral distinctions. Arch. Neurol. 53, 687-690.

Livingston, G., Johnston, K., Katona, C., Paton, J., Lyketsos, C. G., and Old Age Task Force of the World Federation of Biological Psychiatry. (2005). Systematic review of psychological approaches to the management of neuropsychiatric symptoms of dementia. Am. J. Psychiatry 162, 1996-2021.

Logsdon, R. G., Teri, L., Weiner, M. F., Gibbons, L. E., Raskind, M., Peskind, E., Grundman, M., Koss, E., Thomas R. G., and Thal, L. J. (1999). Assessment of agitation in Alzheimer's disease: the agitated behavior in dementia scale. Alzheimer's Disease Cooperative Study. J. Am. Geriatr. Soc. 47, 1354-1358.

Lonergan, E., and Luxenberg, J. (2009). Valproate preparations for agitation in dementia. Cochrane Database Syst. Rev. 3, CD003945.

Lopez, O. L., Becker, J. T., Sweet, R. A., Klunk, W., Kaufer, D. I., Saxton, J., Grundman, M., Koss, E., Thomas, R. G., and Thal, L. J. (2003). Psychiatric symptoms vary with the severity of dementia in probable Alzheimer's disease. J. Neuropsychiatry Clin. Neurosci. 15, 346-5352.

Lövheim, H., Sandman, P. O., Karlsson, S., and Gustafson, Y. (2008). Behavioral and psychological symptoms of dementia in relation to level of cognitive impairment. Int. Psychogeriatr. 20, 777-789.

Lövheim, H., Sandman, P. O., Karlsson, S., and Gustafson, Y. (2009). Sex differences in the prevalence of behavioral and psychological symptoms of dementia. Int. Psychogeriatr. 21, 469-475.

Lyketsos, C. G., Lopez, O., Jones, B., Fitzpatrick, A. L., Breitner, J., and DeKosky, S. (2002). Prevalence of neuropsychiatric symptoms in dementia and mild cognitive impairment: results from the cardiovascular health study. JAMA 288 , 1475-1483.

Lyketsos, C. G., Sheppard, J. M., Steinberg, M., Tschanz, J. A., Norton, M. C., Steffens, D. C., and Breitner, J. 
C. (2001). Neuropsychiatric disturbance in Alzheimer's disease clusters into three groups: the Cache County study. Int. J. Geriatr. Psychiatry 16, 1043-1053.

Lyketsos, C. G., Steinberg, M., Tschanz, J. T., Norton, M. C., Steffens, D. C., and Breitner, J. C. (2000). Mental and behavioral disturbances in dementia: findings from the Cache County Study on Memory in Aging. Am. J. Psychiatry 157, 708-714.

Marshall, G. A., Monserratt, L., Harwood, D., Mandelkern, M., Cummings, J. L., and Sultzer, D. L. (2007). Positron emission tomography metabolic correlates of apathy in Alzheimer disease. Arch. Neurol. 64, 1015-1020.

Massimo, L., Powers, C., Moore, P., Vesely, L., Avants, B., Gee, J., Libon, D. J., and Grossman, M. (2009). Neuroanatomy of apathy and disinhibition in frontotemporal lobar degeneration. Dement. Geriatr. Cogn. Disord. 27, 96-104.

Matsui, T., Nakaaki, S., Murata, Y., Sato, J., Shinagawa, Y., Tatsumi, H., and Furukawa, T. A. (2006). Determinants of the quality of life in Alzheimer's disease patients as assessed by the Japanese version of the Quality of Life-Alzheimer's disease scale. Dement. Geriatr. Cogn. Disord. 21, 182-191.

Matthews, K. L., Chen, C. P., Esiri, M. M., Keene, J., Minger, S. L., and Francis, P. T. (2002). Noradrenergic changes, aggressive behavior, and cognition in patients with dementia. Biol. Psychiatry 51, 407-416.

McKeith, I. G., Dickson, D. W., Lowe, J., Emre, M., O'Brien, J. T., Feldman, H., Cummings, J., Duda, J. E., Lippa, C., Perry, E. K., Aarsland, D., Arai, H., Ballard, C. G., Boeve, B., Burn, D. J., Costa, D., Del Ser, T., Dubois, B., Galasko, D., Gauthier, S., Goetz, C. G., GomezTortosa, E., Halliday, G., Hansen, L. A., Hardy, J., Iwatsubo, T., Kalaria, R. N., Kaufer, D., Kenny, R. A., Korczyn, A., Kosaka, K., Lee, V. M., Lees, A., Litvan, I., Londos, E., Lopez, O. L., Minoshima, S., Mizuno, Y., Molina, J. A., Mukaetova-Ladinska, E. B., Pasquier, F., Perry, R. H., Schulz, J. B., Trojanowski, J. Q., Yamada, M., and Consortium on DLB. (2005). Diagnosis and management of dementia with Lewy bodies: third report of the DLB Consortium. Neurology 65, 1992.

Mirakhur, A., Craig, D., Hart, D. J., McLlroy, S. P., and Passmore, A. P. (2004). Behavioural and psychological syndromes in Alzheimer's disease. Int. J. Geriatr. Psychiatry 19, 1035-1039.

Mitchell, R. A., Herrmann, N., and Lanctôt, K. L. (2011). The role of dopamine in symptoms and treatment of apathy in Alzheimer's disease. CNS Neurosci. Ther. 17, 411-427.

Miyamoto, Y., Tachimori, H., and Ito, H. (2010). Formal caregiver burden in dementia: impact of behavioral and psychological symptoms of dementia and activities of daily living. Geriatr. Nurs. 31, 246-253.

Modrego, P. J., and Ferrández, J. (2004). Depression in patients with mild cognitive impairment increases the risk of developing dementia of Alzheimer type: a prospective cohort study. Arch. Neurol. 61, 1290-1293.

Monastero, R., Mangialasche, F., Camarda, C., Ercolani, S., and Camarda, R. (2009). A systematic review of neuropsychiatric symptoms in mild cognitive impairment. J. Alzheimers Dis. 18, 11-30.

Mossello, E., Ridolfi, A., Mello, A. M., Lorenzini, G., Mugnai, F., Piccini, C., Barone, D., Peruzzi, A., Masotti, G., and Marchionni, N. (2011). Animalassisted activity and emotional status of patients with Alzheimer's disease in day care. Int. Psychogeriatr. 1 , 1-7.

Mukaetova-Ladinska, E. B., Harrington, C. R., Xuereb, J., Roth, M., and Wischik, C. M. (1995). Biochemical, neuropathological, and clinical correlations of neurofibrillary degeneration in Alzheimer's disease," in Treating Alzheimer's and Other Dementias, eds M. Bergener and S. I. Finkel (New York: Springer), 57-80.

Mulin, E., Leone, E., Dujardin, K., Delliaux, M., Leentjen Dessi, B., Tible, O., Agüera-Ortiz, L., Osorio, R. S., Yessavage, J., Dachevsky, D., Verhey, F. R., Cruz Jentoft, A. J., Blanc, O., Llorca, P. M., and Robert, P. H. (2011). Diagnostic criteria for apathy in clinical practice. Int. J. Geriatr. Psychiatry 26, 158-165.

Neary, D., Snowden, J., and Mann, D. (2005). Frontotemporal dementia. Lancet Neurol. 4, 771-780.

Nyatsanza, S., Shetty, T., Gregory, C., Lough, S., Dawson, K., and Hodges, J. R. (2003). A study of stereotypic behaviours in Alzheimer's disease and frontal and temporal variant frontotemporal dementia. J. Neurol. Neurosurg. Psychiatr. 74, 1398-1402.

O’Neil, M. E., Freeman, M., Christensen, V., Telerant, R., Addleman, A., and Kansagara, D. (2011). A Systematic Evidence Review of Nonpharmacological Interventions for
Behavioral Symptoms of Dementia. Washington, DC: Department of Veterans Affairs.

Ostling, S., Gustafson, D., and Waern, M. (2009). Psychotic and behavioural symptoms in a population-based sample of the very elderly subjects. Acta Psychiatr. Scand. 120, 147-152.

Palmer, K., Di Iulio, F., Varsi, A. E., Gianni, W., Sancesario, G., Caltagirone, C., and Spalletta, G. (2010). Neuropsychiatric predictors of progression from amnestic-mild cognitive impairment to Alzheimer's disease: the role of depression and apathy. J. Alzheimers Dis. 20, 175-183.

Pinto, T., Lanctôt, K. L., and Herrmann, N. (2011). Revisiting the cholinergic hypothesis of behavioral and psychological symptoms in dementia of the Alzheimer's type. Ageing Res. Rev. 10, 404-412.

Poulin, S. P., Dautoff, R., Morris, J. C., Barrett, L. F., and Dickerson, B. C. (2011). Amygdala atrophy is prominent in early Alzheimer's disease and relates to symptom severity. Psychiatry Res. 194, 7-13.

Prado-Jean, A., Couratier, P., DruetCabanac, M., Nubukpo, P., BernardBourzeix, L., Thomas, P., Dechamps, N., Videaud, H., Dantoine, T., and Clément, J. P. (2010). Specific psychologicaland behavioral symptoms of depression in patients with dementia. Int. J. Geriatr. Psychiatry 25, 1065-1072.

Prick, A. E., de Lange, J., Scherder, E., and Pot, A. M. (2011). Home-based exercise and support programme for people with dementia and their caregivers: study protocol of a randomised controlled trial. BMC Public Health 11, 894.

Proitsi, P., Lupton, M. K., Reeves, S. J., Hamilton, G., Archer, N., Martin, B. M., Iyegbe, C., Hollingworth, P., Lawlor, B., Gill, M., Brayne, C., Rubinsztein, D. C., Owen, M. J., Williams, J., Lovestone, S., and Powell, J. F. (2012). Association of serotonin and dopamine gene pathways with behavioral subphenotypes in dementia. Neurobiol. Aging 33, 791-803.

Rapp, M. A., Schnaider-Beeri, M., Grossman, H. T., Sano, M., Perl, D. P., Purohit, D. P., Gorman, J. M., and Haroutunian, V. (2006). Increased hippocampal plaques and tangles in patients with Alzheimer disease with a lifetime history of major depression. Arch. Gen. Psychiatry 63, 161-167.

Rapp, M. A., Schnaider-Beeri, M., Purohit, D. P., Perl, D. P., Haroutunian, V., and Sano, M. (2008). Increased neurofibrillary tangles in patients with Alzheimer disease with comorbid depression. Am. J. Geriatr. Psychiatry 16, 168-174.

Reisberg, B., Borenstein, J., Salob, S. P., Ferris, S. H., Franssen, E., and Georgotas, A. (1987). Behavioral symptoms in Alzheimer's disease: phenomenology and treatment. J. Clin. Psychiatry 48(Suppl.), 9-15.

Robert, P. H., Onyike, C. U., Leentjens, A. F. G., Dujardin, K., Aalten, P., Starkstein, S., Verhey, F. R., Yessavage, J., Clement, J. P., Drapier, D., Bayle, F., Benoit, M., Boyer, P., Lorca, P. M., Thibaut, F., Gauthier, S., Grossberg, G., Vellas, B., and Byrne, J. (2009). Proposed diagnostic criteria for apathy in Alzheimer's disease and other neuropsychiatric disorders. Eur. Psychiatry 24, 98-104.

Rocca, P., Leotta, D., Liffredo, C., Mingrone, C., Sigaudo, M., Capellero, B., Rocca, G., Simoncini, M., Pirfo, E., and Bogetto, F. (2010). Neuropsychiatric symptoms underlying caregiver stress and insight in Alzheimer's disease. Dement. Geriatr. Cogn. Disord. 30, 57-63.

Rockwell, E., Choure, J., Galasko, D., Olichney, J., and Jeste, D. V. (2000). Psychopathology at initial diagnosis in dementia with Lewy bodies versus Alzheimer disease: comparison of matched groups with autopsyconfirmed diagnoses. Int. J. Geriatr. Psychiatry 15, 819-823.

Rodda, J., Morgan, S., and Walker, Z. (2009). Are cholinesterase inhibitors effective in the management of the behavioral and psychological symptoms of dementia in Alzheimer's disease? A systematic review of randomized, placebo-controlled trials of donepezil, rivastigmine and galantamine. Int. Psychogeriatr. 21, 813-824.

Rongve, A., Boeve, B. F., and Aarsland, D. (2010). Frequency and correlates of caregiver-reported sleep disturbances in a sample of persons with early dementia. J. Am. Geriatr. Soc 58, 480-486.

Rosen, H. J., Allison, S. C., Schauer, G. F., Gorno-Tempini, M. L., Weiner, M. W., and Miller, B. L. (2005). Neuroanatomical correlates of behavioural disorders in dementia. Brain 128(Pt 11), 2612-2625.

Rosenberg, P. B., Mielke, M. M., Appleby, B., Oh, E., Leoutsakos, J. M., and Lyketsos, C. G. (2011). Neuropsychiatric symptoms in MCI subtypes: the importance of executive dysfunction. Int. J. Geriatr. Psychiatry 26, 364-372. 
Rozzini, L., Vicini Chilovi, B., Conti, M., Delrio, I., Borroni, B., Trabucchi, M., and Padovani, A. (2008). Neuropsychiatric symptoms in amnestic and nonamnestic mild cognitive impairment. Dement. Geriatr. Cogn. Disord. 25, 32-36.

Russ, T. C., Batty, G. D., and Starr, J. M. (2011). Cognitive and behavioural predictors of survival in Alzheimer disease: results from a sample of treated patients in a tertiary-referral memory clinic. Int. J. Geriatr. Psychiatry. doi:10.1002/gps.2795

Ryu, S. H., Ha, J. H., Park, D. H., Yu, J., and Livingston, G. (2011). Persistence of neuropsychiatric symptoms over six months in mild cognitive impairment in community-dwelling Korean elderly. Int. Psychogeriatr. 23, 214-220.

Salzman, C., Jeste, D. V., Meyer, R. E., Cohen-Mansfield, J., Cummings, J., Grossberg, G. T., Jarvik, L., Kraemer, H. C., Lebowitz, B. D., Maslow, K., Pollock, B. G., Raskind, M., Schultz, S. K., Wang, P., Zito, J. M., and Zubenko, G. S. (2008). Elderly patients with dementiarelated symptoms of severe agitation and aggression: consensus statement on treatment options, clinical trials methodology, and policy. J. Clin. Psychiatry 69, 889-898.

Savva, G. M., Zaccai, J., Matthews, F. E., Davidson, J. E., McKeith, I., Brayne, C., and Medical Research Council Cognitive Function and Ageing Study. (2009). Prevalence, correlates and course of behavioural and psychological symptoms of dementia in the population. Br. J. Psychiatry 194, 212-219.

Scarmeas, N., Brandt, J., Albert, M., Hadjigeorgiou, G., Papadimitriou, A., Dubois, B., Sarazin, M., Devanand, D., Honig, L., Marder, K., Bell, K., Wegesin, D., Blacker, D., and Stern, Y. (2005). Delusions and hallucinations are associated with worse outcome in Alzheimer disease. Arch. Neurol. 62, 1601-1608.

Schreinzer, D., Ballaban, T., Brannath, W., Lang, T., Hilger, E., Fasching, P., and Fischer, P. (2005). Components of behavioral pathology in dementia. Int. J. Geriatr. Psychiatry 20, 137-145.

Seitz, D. P., Adunuri, N., Gill, S. S., Gruneir, A., Herrmann, N., and Rochon, P. (2011). Antidepressants for agitation and psychosis in dementia. Cochrane Database Syst. Rev. 2, CD008191.

Selbaek, G., Kirkevold, Ø., and Engedal, K. (2008). The course of psychiatric and behavioral symptoms and the use of psychotropic medication in patients with dementia in Norwegian nursing homes - a 12-month follow-up study. Am. J. Geriatr. Psychiatry 16, 528-536.

Selbæk, G., and Engedal, K. (2012). Stability of the factor structure of the neuropsychiatric inventory in a 31month follow-up study of a large sample of nursing-home patients with dementia. Int. Psychogeriatr. 24, 62-73.

Serra, L., Perri, R., Cercignani, M., Spanò, B., Fadda, L., Marra, C., Carlesimo, G. A., Caltagirone, C., and Bozzali, M. (2010a). Are the behavioral symptoms of Alzheimer's disease directly associated with neurodegeneration? J. Alzheimers Dis. 21, 627-639.

Serra, L., Perri, R., Fadda, L., Padovani, A., Lorusso, S., Pettenati, C., Caltagirone, C., and Carlesimo, G. A. (2010b). Relationship between cognitive impairment and behavioural disturbances in Alzheimer's disease patients. Behav. Neurol. 23, 123-130.

Sink, K. M., Covinsky, K. E., Barnes, D. E., Newcomer, R. J., and Yaffe, K. (2006). Caregiver characteristics are associated with neuropsychiatric symptoms of dementia. J. Am. Geriatr. Soc. 54, 796-803.

Snow, A. L., Kunik, M. E., Molinari, V. A., Orengo, C. A., Doody, R., Graham, D. P., and Norris, M. P. (2005). Accuracy of self-reported depression in persons with dementia. J. Am. Geriatr. Soc. 53, 389-396.

Spalletta, G., Musicco, M., Padovani, A., Rozzini, L., Perri, R., Fadda, L., Canonico, V., Trequattrini, A., Pettenati, C., Caltagirone, C., and Palmer, K. (2010). Neuropsychiatric symptoms and syndromes in a large cohort of newly diagnosed, untreated patients with Alzheimer disease. Am. J. Geriatr. Psychiatry 18, 1026-1035.

Srikanth, S., Nagaraja, A. V., and Ratnavalli, E. (2005). Neuropsychiatric symptoms in dementia-frequency, relationship to dementia severity and comparison in Alzheimer's disease, vascular dementia and frontotemporal dementia. J. Neurol. Sci. 236, 43-48.

Staekenborg, S. S., Su, T., van Straaten, E. C., Lane, R., Scheltens, P., Barkhof, F., and van der Flier, W. M. (2010). Behavioural and psychological symptoms in vascular dementia; differences between small- and large-vessel disease. J. Neurol. Neurosurg. Psychiatr. 81, 547-551.
Staff, R. T., Venneri, A., Gemmell, H. G., Shanks, M. F., Pestell, S. J., and Murray, A. D. (2000). HMPAO SPECT imaging of Alzheimer's disease patients with similar content-specific autobiographic delusion: comparison using statistical parametric mapping. J. Nucl. Med. 41, 1451-1455.

Staffen, W., Bergmann, J., Schönauer, U., Zauner, H., Kronbichler, M., Golaszewski, S., and van der Flier, W. M. (2009). Cerebral perfusion (HMPAO-SPECT) in patients with depression with cognitive impairment versus those with mild cognitive impairment and dementia of Alzheimer's type: a semiquantitative and automated evaluation. Eur. J. Nucl. Med. Mol. Imaging 36, 801-810.

Starkstein, S. E., Mizrahi, R., Capizzano, A. A., Acion, L., Brockman, S., and Power, B. D. (2009). Neuroimaging correlates of apathy and depression in Alzheimer's disease. $J$. Neuropsychiatry Clin. Neurosci. 21, 259-265.

Starr, J. M., and Lonie, J. (2007). Relationship between behavioural and psychological symptoms of dementia and cognition in Alzheimer's disease. Dement. Geriatr. Cogn. Disord. 24, 343-347.

Stavitsky, K., Brickman, A. M., Scarmeas, N., Torgan, R. L., Tang, M. X., Albert, M., Brandt, J., Blacker, D., and Stern, Y. (2006). The progression of cognition, psychiatric symptoms, and functional abilities in dementia with Lewy bodies and Alzheimer disease. Arch. Neurol. 63, 1450-1456.

Steinberg, M., Tschanz, J. T., Corcoran, C., Steffens, D. C., Norton, M. C., Lyketsos, C. G., and Breitner, J. C. (2004). The persistence of neuropsychiatric symptoms in dementia: the Cache County Study. Int. J. Geriatr. Psychiatry 19, 19-26.

Sultzer, D. L., Brown, C. V., Mandelkern, M. A., Mahler, M. E., Mendez, M. F., Chen, S. T., and Cummings, J. L. (2003). Delusional thoughts and regional frontal/temporal cortex metabolism in Alzheimer's disease. Am. J. Psychiatry 160, 341-349.

Sultzer, D. L., Mahler, M. E., Mandelkern, M. A., Cummings, J. L., Van Gorp, W. G., Hinkin, C. H., and Berisford, M. A. (1995). The relationship between psychiatric symptoms and regional cortical metabolism in Alzheimer's disease. J. Neuropsychiatry Clin. Neurosci. 7, 476-484.

Sweet, R. A., Hamilton, R. L., Butters, M. A., Mulsant, B. H., Pollock, B. G.,
Lewis, D. A., Lopez, O. L., DeKosky, S. T., and Reynolds, C. F. III. (2004). Neuropathologic correlates of lateonset major depression. Neuropsychopharmacology 29, 2242-2250.

Sweet, R. A., Hamilton, R. L., Lopez, O. L., Klunk, W. E., Wisniewski, S. R., Kaufer, D. I., Healy, M. T., and DeKosky, S. T. (2000). Psychotic symptoms in Alzheimer's disease are not associated with more severe neuropathologic features. Int. Psychogeriatr. 12, 547-558.

Sweet, R. A., Panchalingam, K., Pettegrew, J. W., McClure, R. J., Hamilton, R. L., Lopez, O. L., Kaufer, D. I., DeKosky, S. T., and Klunk, W. E. (2002). Psychosis in Alzheimer disease: postmortem magnetic resonance spectroscopy evidence of excess neuronal and membrane phospholipid pathology. Neurobiol. Aging 23, 547-553.

Tariot, P. N., Mack, J. L., Patterson, M. B., Edland, S. D., Weiner, M. F., Fillenbaum, G., Blazina, L., Teri, L., Rubin, E., Mortimer, J.A., Stern Y., and the Behavioral Pathology Committee of the Consortium to Establish a Registry for Alzheimer's Disease. (1995). The Behavior Rating Scale for dementia of the consortium to establish a registry for Alzheimer's disease. Am. J. Psychiatry 152, 1349-1357.

Tatsumi, H., Nakaaki, S., Torii, K., Shinagawa, Y., Watanabe, N., Murata, Y., Sato, J., Mimura, M., and Furukawa, T. A. (2009). Neuropsychiatric symptoms predict change in quality of life of Alzheimer disease patients: a two-year follow-up study. Psychiatry Clin. Neurosci. 63, 374-384.

Teaktong, T., Piggott, M. A., Mckeith, I. G., Perry, R. H., Ballard, C. G., and Perry, E. K. (2005). Muscarinic M2 and M4 receptors in anterior cingulate cortex: relation to neuropsychiatric symptoms in dementia with Lewy bodies. Behav. Brain Res. 161, 299-305.

Tekin, S., Mega, M. S., Masterman, D. M., Chow, T., Garakian, J., Vinters H. V., and Cummings, J. L. (2001). Orbitofrontal and anterior cingulate cortex neurofibrillary tangle burden is associated with agitation in Alzheimer disease. Ann. Neurol. 49, 355-361.

Thompson, C., Brodaty, H., Trollor, J., and Sachdev, P. (2010). Behavioral and psychological symptoms associated with dementia subtype and severity. Int. Psychogeriatr. 22, 300-305.

Toyota, Y., Ikeda, M., Shinagawa, S., Matsumoto, T., Matsumoto, N., 
Hokoishi, K., Fukuhara, R., Ishikawa, T., Mori, T., Adachi, H., Komori, K., and Tanabe, H. (2007). Comparison of behavioral and psychological symptoms in early-onset and late-onset Alzheimer's disease. Int. J. Geriatr. Psychiatry 22, 896-901.

Tsai, C. F., Wang, S. J., Zheng, L., and Fuh, J. L. (2010). Category verbal fluency predicted changes in behavioral and psychological symptoms of dementia in patients with Alzheimer's disease. Psychiatry Clin. Neurosci. 64, 408-414.

Tsang, S. W., Francis, P. T., Esiri, M. M., Wong, P. T., Chen, C. P., and Lai, M. K. (2008). Loss of $[3 \mathrm{H}] 4$ DAMP binding to muscarinic receptors in the orbitofrontal cortex of Alzheimer's disease patients with psychosis. Psychopharmacology (Berl.) 198, 251-259.

Tschanz, J. T., Corcoran, C. D., Schwartz, S., Treiber, K., Green, R. C., Norton, M. C., Mielke, M. M., Piercy, K., Steinberg, M., Rabins, P. V., Leoutsakos, J. M., Welsh-Bohmer, K. A., Breitner, J. C., and Lyketsos, C. G. (2011). Progression of cognitive, functional, and neuropsychiatric symptom domains in a population cohort with Alzheimer dementia: the Cache County Dementia Progression study. Am. J. Geriatr. Psychiatry 19, 532-542.

Tsopelas, C., Stewart, R., Savva, G. M., Brayne, C., Ince, P., Thomas, A., Matthews, F. E., and Medical Research Council Cognitive Function and Ageing Study. (2011). Neuropathological correlates of late-life depression in older people. Br. J. Psychiatry 198, 109-114.

Tsuang, D., Larson, E. B., Bolen, E., Thompson, M. L., Peskind, E., Bowen, J., McCormick, W., Teri, L.,
Kukull, W., Vavrek, D., Montine, T., and Leverenz, J. B. (2009). Visual hallucinations in dementia: a prospective community-based study with autopsy. Am. J. Geriatr. Psychiatry 17, 317-323.

Tun, S. M., Murman, D. L., Long, H. L., Colenda, C. C., and von Eye, A. (2007). Predictive validity of neuropsychiatric subgroups on nursing home placement and survival in patients with Alzheimer disease. Am. J. Geriatr. Psychiatry 15, 314-327.

Tunnard, C., Whitehead, D., Hurt, C., Wahlund, L. O., Mecocci, P., Tsolaki, M., Vellas, B., Spenger, C., Kloszewska, I., Soininen, H., Lovestone, S., Simmons, A., and AddNeuroMed Consortium. (2011). Apathy and cortical atrophy in Alzheimer's disease. Int. J. Geriatr. Psychiatry 26, 741-748.

Verkaik, R., Nuyen, J., Schellevis, F., and Francke, A. (2007). The relationship between severity of Alzheimer's disease and prevalence of comorbid depressive symptoms and depression: a systematic review. Int. J. Geriatr. Psychiatry 22, 1063-1086.

Vogel, A., Waldorff, F. B., and Waldemar, G. (2010). Impaired awareness of deficits and neuropsychiatric symptoms in early Alzheimer's disease: the Danish Alzheimer Intervention Study (DAISY). J. Neuropsychiatry Clin. Neurosci. 22, 93-99.

Wancata, J., Benda, N., Meise, U., and Windhaber, J. (2003). Non-cognitive symptoms of dementia in nursing homes: frequency, course and consequences. Soc. Psychiatry Psychiatr. Epidemiol. 38, 637-643.

Weamer, E. A., Emanuel, J. E., Varon, D., Miyahara, S., Wilkosz, P. A., Lopez, O. L., Dekosky, S. T., and
Sweet, R. A. (2009). The relationship of excess cognitive impairment in MCI and early Alzheimer's disease to the subsequent emergence of psychosis. Int. Psychogeriatr. 21, 78-85.

Weitzel, T., Robinson, S., Mercer, S., Berry, T., Barnes, M., Vollmer, C., Foster, T., Friedrich, L., Allen, L., Holmes, J., and Kirkbride, G. (2011). Pilot testing an educational intervention to improve communication with patients with dementia. $J$ Nurses Staff. Dev. 27, 220-226.

Wetzels, R. B., Zuidema, S. U., de Jonghe, J. F., Verhey, F. R., and Koopmans, R. T. (2010). Course of neuropsychiatric symptoms in residents with dementia in nursing homes over 2year period. Am. J. Geriatr. Psychiatry 18, 1054-1065.

Wilson, R. S., Schneider, J. A., Bienias, J. L., Arnold, S. E., Evans, D. A., and Bennett, D. A. (2003). Depressive symptoms, clinical AD, and cortical plaques and tangles in older persons. Neurology 61, 1102-1107.

Yesavage, J. A., Friedman, L., AncoliIsrael, S., Bliwise, D., Singer, C., Vitiello, M. V., Monjan, A. A., and Lebowitz, B. (2003). Development of diagnostic criteria for defining sleep disturbance in Alzheimer's disease. J. Geriatr. Psychiatry. Neurol. 16, 131-139.

Youn, J. C., Lee, D. Y., Jhoo, J. H., Kim, K. W., Choo, I. H., and Woo, J. I. (2011). Prevalence of neuropsychiatric syndromes in Alzheimer's disease (AD). Arch. Gerontol. Geriatr. 52, 258-263.

Zubenko, G. S., Moossy, J., Martinez, A. J., Rao, G., Claassen, D., Rosen, J., and Kopp, U. (1991). Neuropathologic and neurochemical correlates of psychosis in primary dementia. Arch. Neurol. 48, 619-624.
Zuidema, S. U., de Jonghe, J. F., Verhey, F. R., and Koopmans, R. T. (2007). Neuropsychiatric symptoms in nursing home patients: factor structure invariance of the Dutch nursing home version of the neuropsychiatric inventory in different stages of dementia. Dement. Geriatr. Cogn. Disord. 24, 169-176.

Zuidema, S. U., de Jonghe, J. F., Verhey, F. R., and Koopmans, R. T. (2010). Environmental correlates of neuropsychiatric symptoms in nursing home patients with dementia. Int. J. Geriatr. Psychiatry 25, 14-22.

Conflict of Interest Statement: The authors declare that the research was conducted in the absence of any commercial or financial relationships that could be construed as a potential conflict of interest.

Received: 07 February 2012; paper pending published: 24 February 2012; accepted: 13 April 2012; published online: 07 May 2012.

Citation: Cerejeira J, Lagarto $L$ and Mukaetova-Ladinska EB (2012) Behavioral and psychological symptoms of dementia. Front. Neur. 3:73. doi: 10.3389/fneur.2012.00073

This article was submitted to Frontiers in Dementia, a specialty of Frontiers in Neurology.

Copyright () 2012 Cerejeira, Lagarto and Mukaetova-Ladinska. This is an openaccess article distributed under the terms of the Creative Commons Attribution Non Commercial License, which permits non-commercial use, distribution, and reproduction in other forums, provided the original authors and source are credited. 